\title{
A LABORATORY ASSESSMENT OF THE RELATIVE IMPORTANCE OF TURBULENCE, PARTICLE COMPOSITION, AND CONCENTRATION IN LIMITING MAXIMAL FLOC SIZE AND SETTLING BEHAVIOUR.
}

By

Timothy George Milligan

Submitted in partial fulfilment of the requirements for the degree of Master of Science

at

Dalhousie University

Halifax, Nova Scotia

December, 1996

(C) Copyright by Timothy George Milligan 
Acquisitions and Bibliographic Services

395 Wellington Street Ottawa ON K1A ON4 Canada
Acquisitions et

services bibliographiques

395, ne Wellington

Ottawa ON KiA ON4

Canada
The author has granted a nonexclusive licence allowing the National Library of Canada to reproduce, loan, distribute or sell copies of this thesis in microform, paper or electronic formats.

The author retains ownership of the copyright in this thesis. Neither the thesis nor substantial extracts from it may be printed or otherwise reproduced without the author's permission.
L'auteur a accordé une licence non exclusive permettant à la Bibliothèque nationale du Canada de reproduire, prêter, distribuer ou vendre des copies de cette thèse sous la forme de microfiche/film, de reproduction sur papier ou sur format électronique.

L'auteur conserve la propriété du droit d'auteur qui protège cette thèse. $\mathrm{Ni}$ la thèse ni des extraits substantiels de celle-ci ne doivent être imprimés ou autrement reproduits sans son autorisation. 


\section{Contents}

Title Page

Abstract

vi

Acknowledgements

vii

Dedication

viii

List of Tables

ix

List of Figures

$\mathbf{x}$

1 Introduction 1

1.1 Introduction 1

1.2 Rationale 2

1.3 Previous Work 5

2 Methods 9

2.1 Image acquisition 9

2.2 Image Analysis 15

2.3 Materials 23

2.4 Flocculator $\quad 27$

2.5 Experimental Design and Procedures 33

2.6 Data Reduction and Analysis 35

2.6.1 In situ Particle Size $\quad 35$

2.6.2 Settling Velocity 38

2.6.3 Statistical Analysis $\quad 38$

3 Maximal Floc Size Results 39 
5 Discussion and Conclusion 56

5.1 Discussion 56

5.2 Conclusion $\quad 59$

$\begin{array}{ll}\text { Appendices } & 62\end{array}$

List of Symbols

$\begin{array}{ll}\text { References } & 65\end{array}$ 


\begin{abstract}
The fate of fine particulate material in aquatic environments is closely linked to aggregation and disaggregation processes. Understanding the mechanisms controlling these processes is fundamental to the development of predictive models of fate and effects for particulate discharges in the coastal zone from such sources as offshore hydrocarbon exploration and development. One of the variables required for the development of these models is maximal floc size. Using a non-invasive imaging technique, the significance of turbulence, composition, and concentration on maximal floc size in an inverting column flocculator was determined for materials commonly discharged during offshore hydrocarbon development. The settling velocity of the suspension was determined from volume concentrations of samples obtained by pipette during still water settling in a manner similar to that of Owen tubes. After 20 hours, both maximal floc size and settling velocity showed a highly significant dependence on turbulence and type of material in suspension but showed no effect from concentration.
\end{abstract}




\section{ACKNOWLEDGEMENTS}

Sincere thanks are given to John Conrod at the Bedford Institute of Oceanography whose ability to turn waving arms and strange ideas into operating instruments is priceless, to Paul Hill for the help and direction, but mostly for the many fun hours of talking floc, and to Dianne and Alexis for Christmas. 


\title{
DEDICATION
}

\author{
To \\ Kate Kranck \\ $1937-1992$
}

I wish you could have seen the floc at CoPan. 


\section{List of Tables}

Table 2.1: Listing of experiment conditions and results

Table 3.1: Results of ANOVA of factors and maximal floc size $\left(D_{25}\right)$

Table 3.2: Levels of significance for interactions of factors and $D_{25}$

Table 4.1: Results of ANOVA of factors and settling velocity $\left(w_{25}\right)$

Table 4.2: Levels of significance for interactions of factors and $w_{25}$ 


\section{List of Figures}

2.1: Benthos 373 Plankton Silhouette Camera.

2.2: Comparison between in situ and Coulter Counter size distributions.

2.3: High and low concentration silhouette images from 373 camera.

2.4: Particle size distributions from image analysis of images in fig. 2.3.

2.5: Magnified section of 2.3A showing effect of watershed filter.

2.6: Particle size distributions showing effect of watershed filter.

2.7: Particle size distributions for materials used in experiment.

2.8: Camera and column flocculator.

3.1: In situ particle size distributions from flocculator.

4.2: Plots of percent total cumulative volume vs time. 


\section{CHAPTER 1:}

\subsection{Introduction:}

The equilibrium size distribution of a flocculated suspension can be considered a balance between particle aggregation and disaggregation. Aggregation and disaggregation, through their effects on packing and settling rate, exert strong controls over the fate of fine particles in the marine environment. Missing in our understanding of these processes is a clear definition of the factors that limit maximal floc size in the sea. Given the importance of aggregation and disaggregation in a variety of applied fields, numerous laboratory studies have focused on the control of floc size and its effect on settling behaviour. In general, these investigations have found that maximal floc size decreases with increasing fluid shear (e.g. Tambo and Hozumi, 1979) and that particle composition affects maximal floc size (e.g. Kranck and Milligan, 1980). Some work has also been carried out on the effect of suspension concentration, yielding ambiguous results (e.g. Tsai et al., 1987, Oles, 1991).

Applying the results of these past studies to define the controls of floc size in the sea is problematic for three reasons: first, typical shear rates in laboratory experiments such as those of Tsai et al., (1987), Burban et al., (1989), far exceed those encountered in nature, second, the composition of marine particles differs from those typically used in laboratory studies with unknown consequences, and third, some of the only work on 
disaggregation of natural mud flocs suggests that high concentrations reduce maximal floc size, yet workwith more idealised suspensions shows the opposite effect. With these problems in mind, the goal of this study is to define in the laboratory the relative importance of turbulence, composition and concentration in limiting maximal floc size in suspensions of environmentally relevant particles exposed to turbulent energy levels and suspension concentrations more closely approximating those found in the coastal zone.

\subsection{Rationale:}

The need for research into the behaviour of fine particulate material in the coastal zone is evidenced by the recent work on offshore disposal of drilling wastes from hydrocarbon development on the continental shelf. In 1988, the Canadian Government established a moratorium on hydrocarbon exploration on George's Bank as a result of pressure from the fishing industry and environmental groups. Many questions about the potential impact of hydrocarbon development on the lucrative George's Bank fishery were raised at that time. On George's Bank, the most important commercial species is the sea scallop, Placopecten magelanicus, which accounts for over $70 \%$ of the value of the fishery resource. Cranford and Gordon $(1991,1992)$ have shown that lethal and sublethal effects occur in sea scallops when exposed to drilling muds and some of their component materials. Their work has shown that adult sea scallops have a low tolerance to the presence of drill wastes in their diet. A prolonged, intermittent exposure to concentrations 
as low as a few $\mathrm{mg} \mathrm{l}^{-1}$ can reduce scope for growth and, for some component materials, cause mortality.

In general, the view of disposal of fine particulate material on the continental shelf has been that the low settling velocity of the constituent particles results in rapid dispersion, so concentrations fall quickly below that at which impact would occur. It is more likely, however, that flocculation of the wastes discharged in association with drilling would increase the settling velocity of the fine particle component (Kranck, 1980, Kranck, 1986). Settling velocities greater than $1 \mathrm{~mm} \mathrm{~s}$ are common for aggregates in coastal environments (Alldredge and Gotschalk, 1989, Syvitski et al., 1995, Fennessey et al., 1994). Settling velocities of this order could result in the delivery of fine particulate material to the bottom on George's Bank where ingestion by scallops could occur (Hannah et al., 1995).

Evidence of flocculation of drilling muds in the vicinity of an active offshore drilling operation has been reported by Muschenheim et al., (1995a, b) using video imaging techniques and particle size distribution analysis as a tracer for the presence of drill mud in suspended and bottom sediments. Studies conducted at various times of the year in the vicinity of Pan Canadian Ltd's (formerly Lasmo Nova Scotia Ltd.) drilling platform Rowan Gorilla III (RGII) located at the Cohasset and Panuke (CoPan) fields south of Sable Island, have shown different areal extents of coverage and form of flocculated 
material in the water column and on the bottom. In an initial study conducted during active drilling with water based mud, Niskin bottle samples collected at the surface and suspended sediment samples collected with a specialised near bottom suspended sediment sampler (BOSS) found significant quantities of bentonite in the discharge plume and in the bottom $0.5 \mathrm{~m}$ at stations near the rig (Muschenheim et al., 1995a). Bentonite, one of the major components of the gel muds used on the Scotian Shelf, has a disaggregated grain size spectra quite distinct from naturally occurring inorganic material. A second study using a high-resolution bottom-looking video camera found a mat of flocculated material containing bentonite in association with the RGIII at the end of a calm summer period during which drilling was carried out. Floc coverage on the bottom ranged from over $90 \% 0.3 \mathrm{~km}$ west of the RGIII to $20 \% 15 \mathrm{~km}$ west and trace amounts $8 \mathrm{~km}$ to the north. Sampling of the benthic boundary layer (BBL) with the BOSS during a tidal cycle revealed that flocs containing drill mud residue were resuspended at $u_{100}>0.2 \mathrm{~m} \mathrm{~s}^{-1}$ (Muschenheim et al., 1995a). Sampling conducted in the spring during a production phase with no drilling, revealed very high concentrations of large flocs in suspension. Concentrations increased dramatically as the RGIII was approached from all quadrants and reached a maximum within $500 \mathrm{~m}$ of the rig (Muschenheim et al., 1995a). Although the floc concentration was so high that the bottom was effectively occluded at stations within $1 \mathrm{~km}$, brief glimpses through the 'floc storm' revealed flocculated material on the bottom. Produced water, water associated with the oil bearing formation and production phase of the field which is separated from the oil on board, was being discharged at that 
time. The produced water discharge from the CoPan operation contains very high levels of ammonia $\left(-35 \mathrm{mg} \mathrm{I}^{-1}\right)$, manganese and iron (Pan Canadian Ltd.). A localised phytoplankton bloom resulting from elevated ammonia concentrations coupled with precipitation of the iron and manganese in the water column could have been the source of the abnormally high concentrations of floc found. Evidence collected on four separate occasions on Sable Bank using silhouette photography suggests that flocs on the order of 500-2000 $\mu \mathrm{m}$ are common (unpubl. data) and laboratory experiments have found settling velocities for drill mud flocs of up to $0.02 \mathrm{~m} \mathrm{~s}^{-1}$ in the laboratory (Muschenheim and Milligan, 1996).

The moratorium on hyrdocarbon exploration, scheduled to be lifted in 2000 , is presently under review and there is a need for models to predict possible zones of impact from development. Modelling of a zone of impact incorporating the results of flocculation studies in the field and laboratory has been undertaken. One component of the impact model is a sediment transport model developed for the dispersion and transport of sediment in the BBL (Hannah et al., 1995). Using settling velocities from the laboratory studies and a new method to describe shear dispersion, concentration plots for material accumulating in the BBL have been derived for theoretical discharges on George's Bank and the Scotian Shelf. Concentration plots for the spatially varying case are presently being evaluated. Crucial to the further development of the impact model is the ability to 
describe flocculation processes in the marine environment, especially with regard to flocculation rate, maximum floc size and settling velocity.

\subsection{Previous work:}

Floc formation rate increases with turbulence and yet the same hydrodynamic forces limit floc growth (van Leussen, 1988). This effect has been observed in the field in in situ studies of flocs over a tidal cycle (Kranck and Milligan, 1992) and in relationship to regions of different turbulence within an estuary (Eisma, 1986, Luettich , Jr. et al., 1993, Berhane et al., in press). In laboratory studies, aggregates have been formed using many different types of flocculators ranging from shaken bottles (Kranck, 1986) through simple annular flumes (e.g. Krone, 1962, Postma,1967, Mehta and Partheniades, 1975, Muschenheim et al., 1989), to elaborate flocculators such as those of Tambo and Hozumi (1979) or Tsai et al., (1987). Flocculators of two basic types, paddle and couette, have been used in experiments examining the effect of turbulence, usually expressed as energy dissipation rate or shear, on floc size. Several studies, predominantly using latex beads or pure clay suspensions with added flocculants have demonstrated a strong negative correlation between floc size and turbulence (e.g. Tambo and Hozumi, 1979, Pandya and Spielman, 1982, Oles, 1991, Spicer and Pratsinis, 1996). This inverse relationship has also been shown for natural sediments in both fresh and salt water (Tsai et al., 1987, Burban et al., 1989). Shear rates in the flocculators used range from $15 \mathrm{~s}^{-1}$ (Pandya and Spielman, 1982) to $400 \mathrm{~s}^{-1}$ (Burban et al., 1989), with most experiments being run at rates 
of shear over $50 \mathrm{~s}^{-1}$. By comparison, shear values calculated from $\mathrm{u}_{*}$ values for current meters moored in the very energetic benthic boundary layer on George's Bank reached only $36 \mathrm{~s}^{-1}$ at $1 \mathrm{~m}$ above the bottom during maximum tidal current (Muschenheim et al., 1995a).

Researchers have investigated the role of particle adhesion on maximal floc size and have shown that, for instance, particle adhesion and floc stability depend on the effect of polymer concentration on particle surfaces (Muhle, 1993) and that maximum floc size increases with increased concentrations of flocculant (e.g. Tambo and Hozumi, 1979, Spicer and Pratsinis, 1996). Burban et al. (1989) used lake sediments in their investigations and showed a decrease in floc size in seawater when compared to freshwater and with sediments treated to remove organic material in comparison with untreated. Field and laboratory investigations of naturally occurring particle flocculation suggest that long chain polysaccharide exudates from phytoplankton play an important role in controlling particle stickiness in the ocean (Passow et al., 1994). Presumably, the composition of the sediment in suspension will play an important part in determining maximum floc size since the bridging strength between particles will vary (Muhle, 1993).

Work on the effect of concentration on maximal floc size has not produced such a clear picture as that for the other two factors. Aggregation theory suggests that higher concentrations of particles will yield larger aggregates. However, concentration has also 
been shown to have a negative effect on maximum floc size (Tsai et al., 1987). Using lake sediments in a couette flocculator, equilibrium floc size decreased with increasing sediment concentrations from 50 to $800 \mathrm{mg} \mathrm{l}^{-1}$ at a shear of $200 \mathrm{~s}^{-1}$. Based on these results, Lick and Lick (1988) suggested that collisions between flocs were more important than fluid shear for disaggregation under some conditions, and added a breakup term due to particle collisions to their aggregation model. The findings of Tsai et al., (1987) were replicated by Burban et al., (1989) and also by Lick et al., (1993) using differential settling as the flocculation mechanism instead of shear. Work by Oles (1991) using latex beads at concentrations of 1 and $5 \mathrm{ppm}$, also in a couette flocculator, found that high concentration produced a larger stable size than low concentration for all treatments over a range of shears from 25 to $150 \mathrm{~s}^{-1}$. Field data also seem to contradict the inverse relationship between concentration and floc size and support the simpler view of increasing size with concentration. For example, maximal floc sizes in the Dollard Estuary occurred during or just after maximum suspended sediment concentrations on the ebb tide (Eisma and Li, 1993). Similarly, a strong positive correlation was found between maximum floc size and concentration on the Amazon Shelf using image analysis of silhouette photographs (Berhane et al., in press).

In the development of aggregation models it must first be decided what controls the creation of a stable floc population. To determine which of the above factors, turbulence, composition, and concentration, will affect maximal floc size and hence influence settling behaviour, flocculated suspensions of three materials associated with waste discharges 
from offshore hydrocarbon development were examined under two different turbulent conditions and two concentrations in a flocculator using seawater as the suspension medium. Using the in situ size distribution for aggregates in suspension and the change in volume concentration of the suspension over time during settling, the significance of the three factors on maximal floc size and settling velocity was evaluated. 


\section{CHAPTER 2.}

\subsection{Image acquisition:}

Due to their fragile nature, it is next to impossible to obtain accurate measurements of aggregates if they are removed from the environment in which they were formed or are subjected to changes in the turbulence prior to measurement (Kranck and Milligan, 1980, Gibbs, 1981, 1982, Gibbs and Konwar, 1982, Ten Brinke, 1994, Milligan, 1995). The accurate analysis of floc size requires a non-invasive sizing method. For this study, a Benthos 373 plankton silhouette camera used in previous studies of flocculated material was used to obtain maximal floc diameter without disturbing the flocs in suspension (Fig. 2-1).

The analysis of in-situ particle size and the determination of settling velocities of flocculated suspensions has dominated a large part of aquatic research in recent years (e.g. Puls et al., 1988, Heffler et al., 1991, Van Leussen and Cornelisse, 1993, Fennessey et al., 1994, Ten Brinke, 1994). For many years particle sizing using, for instance, Coulter Counters was carried out on water samples collected by bottle casts or by pumping. Visual evidence collected by divers and underwater cameras seemed to contradict the small particle sizes obtained from particle size analysers and eventually led to the realisation that the size of the material in suspension is not conserved during sampling. This realisation brought forth a number of different in-situ techniques for studying the size and form of suspended sediments, one of the earliest of which was the 


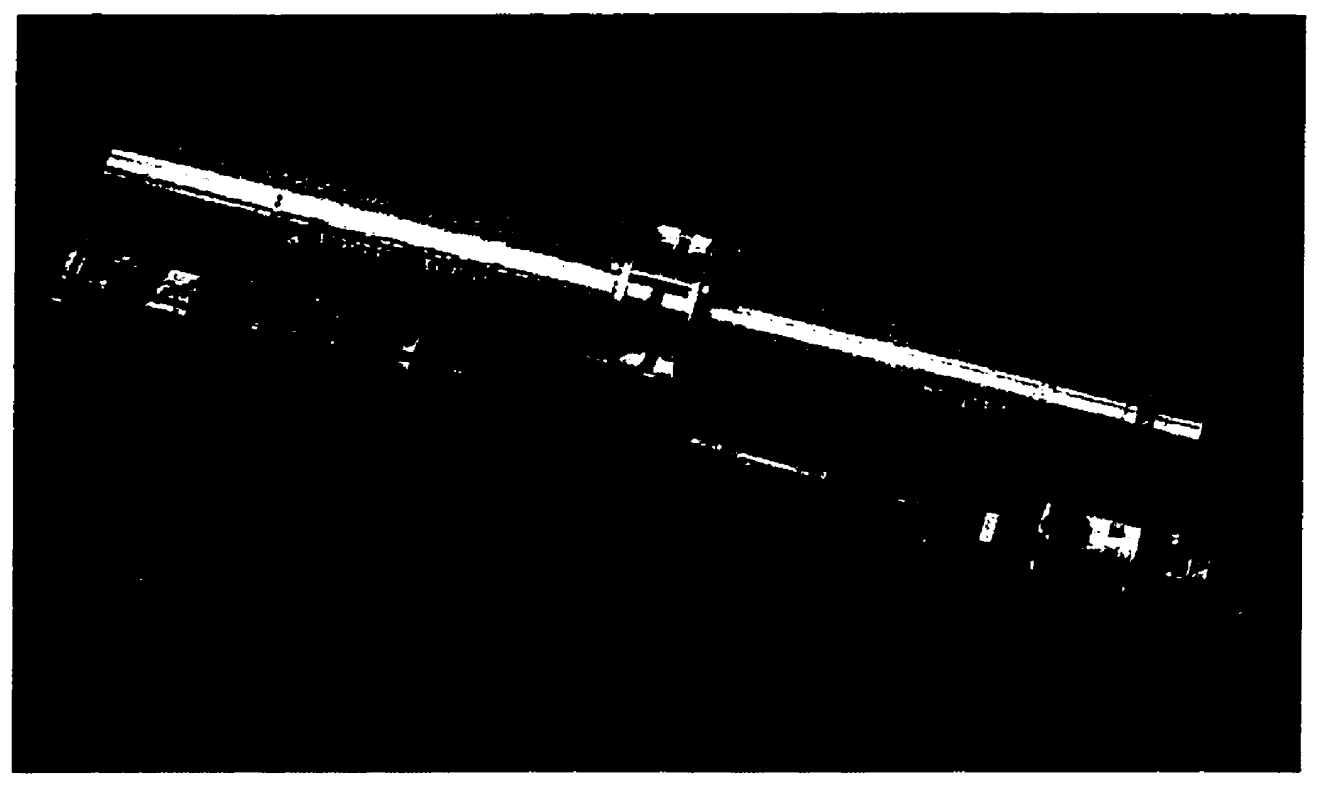

Figure 2.1: Benthos 373 Plankton Silhouette camera with camera (left) and flash (right) units removed from pressure housings. For the experiment the glass plates between the housings were removed 
Benthos 373 plankton silhouette camera. Originally designed to calculate the abundance of zooplankton species by photographing a stream of material at the cod end of a plankton net, the 373 camera has proven to be very useful for the in-situ study of suspended particulate material.

Silhouette photography was first used to identify active biological samples in a laboratory setting (Edgerton, 1979, Ortner et al., 1979). This concept was adapted for underwater use in co-operation with Benthos Inc., Falmouth, Ma. (Edgerton et al., 1981) and originally used to identify species and abundance of plankton in the water column (Ortner et al., 1981). Eisma et al., (1983) used the 373 camera in the Ems estuary to conduct one of the first in situ particle size studies. Using the images from the camera and a simple form of image analysis, they showed that the size of the aggregates in suspension was as much as an order of magnitude greater in both diameter and equivalent volume than that found using a Coulter Counter (Fig. 2). This study also showed that floc characteristics varied in both size and configuration over a tidal period. Kranck and Milligan (1992) used image analysis of photos obtained with the 373 camera in San Francisco Bay to describe the sediment dynamics in the San Rafael region of the Harbour. Results from an 11 hour anchor station showed a rapid increase in the in situ size of the suspended sediment as the tidal current decreased. Rapid clearing of the water column occurred during the period of floc growth. A relationship between the maximum disaggregated inorganic grain size in suspension and the size of the in situ aggregate particles was 


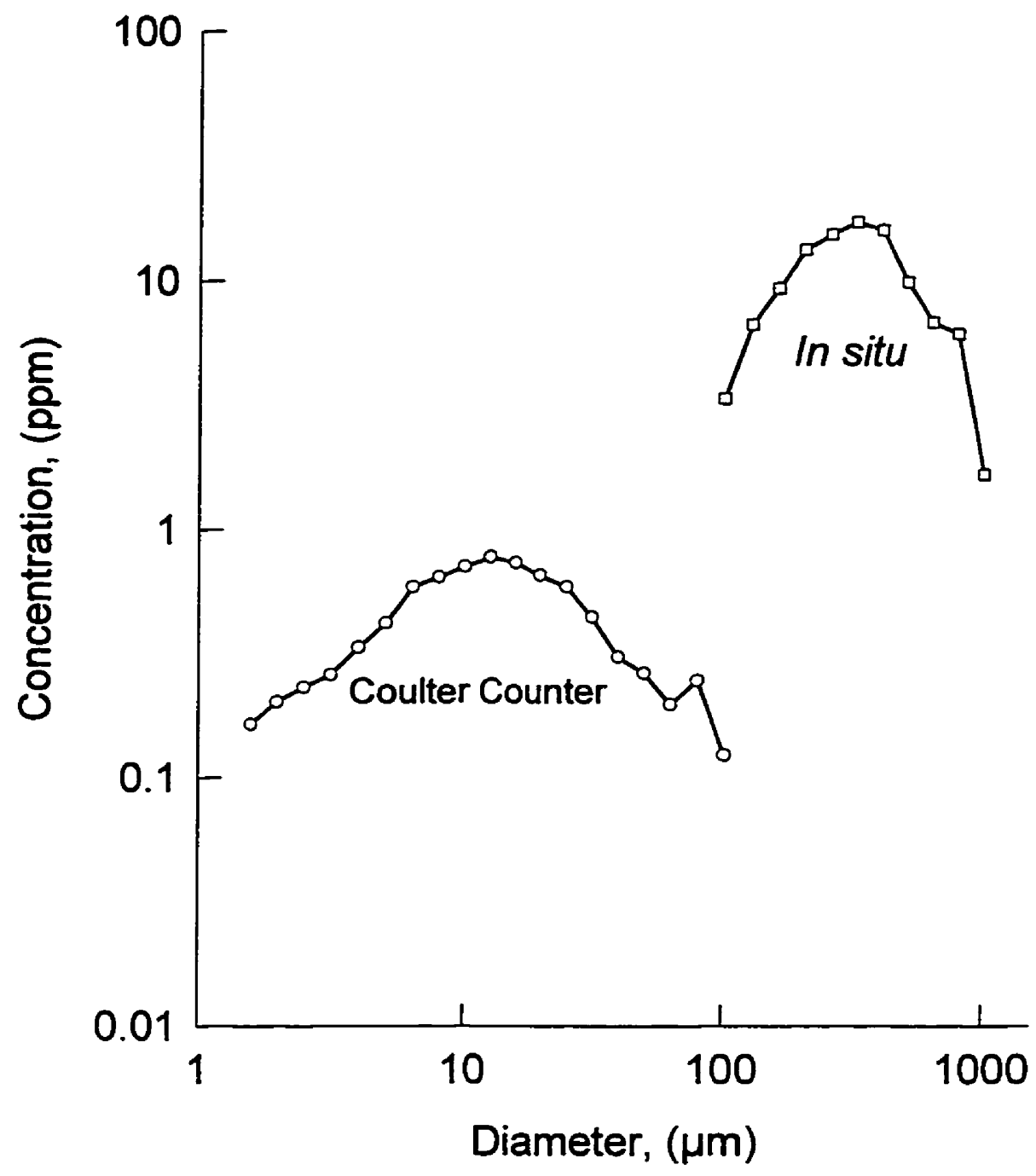

Figure 2.2: Comparison between in situ size distribution from image analysis of silhouette photo (squares) and Coulter Counter (circles) size distribution for a sample collected by Niskin bottle at the same depth in Saint John Harbour, N.B. showing order of magnitude difference in diameter and volume. 
shown. Using images of a flocculated suspension of Elbe River water held in a $5 \mathrm{~m}$ diameter carousel flume, Milligan (1995) demonstrated the same rapid change in the size distribution. In that experiment, the modal size of the aggregates in suspension doubled in less than 8 minutes after stirring of the mesocosm ended. Similar to the results in San Francisco Harbour, the increase in floc size preceded a very rapid clearing of the water column.

The first direct evidence of post bloom phytoplankton aggregation and sinking was obtained with the 373 camera in Bedford Basin, N.S. (Kranck and Milligan, 1988). In a series of vertical casts carried out over several days they recorded the transition from individual chains of the diatom Chaetocerous to large aggregates on the order of 1-2 mm. Prior to the formation of the aggregates, the diatoms were confined to the region above the pycnocline. Kranck et al. (1993) used the 373 camera and two other methods to show that the in situ particle size distribution of suspended material is similar in both fresh and salt water environments. The size distributions of aggregates in rivers in Southern Ontario, collected by submerging an inverted microscope settling chamber and then analysing samples with an inverted microscope, showed good agreement with results from the 373 camera. The shape of the size distributions from these two methods also agreed with those of Eisma et al. $(1990,1992)$ from a studies conducted using 1:10 and 1:1 magnification cameras in configurations similar to the 373 camera. In situ size spectra for the suspended flocs from all three studies seemed to indicate that little or no volume 
of material is found independent of the macro-aggregates in suspension. Most recently, the camera has been used to examine the behaviour and dispersal of fine particulate drilling wastes on the Scotian Shelf (Muschenheim et al., 1995a,b). In a novel application of the silhouette camera, Muschenheim (1987) used it to study the behaviour of suspension feeding polychaetes on a tidal flat. Silhouette images at the sediment-water interface were used to measure the temporal variability in seston concentration in the near bottom region.

The 373 camera consists of two stainless steel pressure cases, one holding a $35 \mathrm{~mm}$ camera and the other a 'point source' $E G+G$ flash tube. The units are mounted directly opposite each other, separated by a gap of $65 \mathrm{~mm}$ (fig. 1). Normally, 12 or $18 \mathrm{~mm}$ optical quality glass plates are used to define a sensing zone between the two housings. The flash is focused through the sensing zone onto the film by a pair of $254 \mathrm{~mm}$ focal length condenser lens. The camera uses a reversed Computar $55 \mathrm{~mm}, \mathrm{f} 1.9$ enlarger lens to focus the silhouette of particles found in a circular section of the region between the housings which is $74 \mathrm{~mm}$ in diameter. A high intensity data chamber imprints the film with a time code of minutes and seconds. Images were recorded on Kodak 5302, fine grain release positive film $\left(A S A \approx 3,125\right.$ lines $\mathrm{mm}^{-1}$ ) and the exposed film was developed with Kodak Kodalith developer to maximise contrast. The photo negatives were enlarged on a slide duplicator using Kodak Technical Pan film developed in $\mathrm{HC} 110$ developer prior to digitisation at $2048 \times 3072$ pixel resolution on Kodak Photo-CDs. Enlarging the negatives 
increased the resolution of the Kodak Photo-CD scanner from $43 \mu \mathrm{m}$ pixel $^{-1}$ on the original image to approximately $26 \mu \mathrm{m}$ pixel $^{-1}$ on the duplicated image. The 256 grey scale images were imported into the program Kodak Photo-Edge where they were cropped and stored in TIFF format. The size of the cropped section varied in each image depending on the concentration of particles in suspension.

\subsection{Image analysis:}

One of the greatest problems encountered in the studies above was the time required to carry out particle size analysis of photographs. Acquisition of several hundred images is routine during deployments of the 373 camera, and until recently, image analysis has been limited to examination of the negatives under a microscope either by eye or with very slow automated techniques. In the studies carried out by Kranck and Milligan (1992, 1993) and Milligan (1995), an automated microscope based image analysis system was used. Processing of an image took on the order of two hours to complete. For this study a new PC-based image analysis protocol using Kodak Photo-CD digitisation of the photonegatives was developed, reducing analysis time for an image to less than 15 minutes. During the development of this new protocol two different image analysis programs were evaluated: MOCHA, from Jandel Scientific Inc., San Rafael, Ca. and Image Pro Plus (IPP) from MediaCybernetics Inc., Silver Spring, Md.. Results from the two new programs were compared with those from the Wild Leitz TAS Plus system used previously (Dabros and Mudie, 1986, Kranck and Milligan, 1992, Milligan, 1995). 
The method of determining the particle size distributions from the digitised photo negatives is similar for most image analysis packages available. Although different packages use slightly different algorithms and nomenclature, the fundamentals of image processing remain the same (for review see Russ (1995)). In both of the PC-based programs that were evaluated, a two-point spatial calibration was carried out using the diameter of an entire image. The calibration information was then used to calibrate each subsequent image so that the results from object measurement were reported in micrometres. In MOCHA, image contrast was increased by taking a section of the 256 grey scale histogram in which the majority of the grey scale values for the image were found and re-mapping them. Following this 'histogram stretch', a $3 \times 3$ median filter was applied to sharpen object edges. To separate touching objects a series of algorithms had to be applied. An erosion filter with an edge speed of 5 was used to initially separate objects. The remaining objects were then dilated using a 'don't merge' filter which kept a one pixel border between objects as they overlapped during dilation. The separation was completed by carrying out a Boolean addition with the original image to re-establish the image borders with the objects separated. The image was then thresholded manually and the area of each object $\left(\mu \mathrm{m}^{2}\right)$ was recorded and converted to equivalent spherical volume (Milligan and Kranck, 1991, Milligan, 1995).

In IPP, the calibrated grey scale image was optimised to best LUTs (look up table of pixel brightness, contrast and gamma) automatically. A $3 \times 3$ median filter was applied to 
sharpen object edges and the threshold for image detection was set manually to prevent over detection in the high concentration images. A watershed filter was applied to the thresholded image to separate touching objects. The watershed filter uses an Euclidean distance map to determine the distance of each pixel in a object from its nearest boundary (Russ, 1995). Using this map, a series of dilations are applied with pixels between objects remaining off. Average diameter $(\mu \mathrm{m})$, derived from the average length of diameters measured at $5^{\circ}$ intervals around the centroid of each thresholded object, and area $\left(\mu \mathrm{m}^{2}\right)$ were measured. The stored values were converted to equivalent spherical volumes for the objects detected and the concnetration, volume of particles per volume of water expressed as parts per million (ppm) was calculated (Milligan and Kranck, 1991).

To use the 373 camera as a quantitative analysis tool requires precise size analysis of the captured images. Image analysis, unfortunately, can be somewhat subjective in that the levels at which an image is thresholded and the degree to which the image is preprocessed using various filters can alter the size distribution dramatically. To examine the robustness of the image analysis protocols a high and a low-concentration image of a flocculated suspension from an experiment carried out in a large carousel flume, (Milligan, 1995), were examined with each method (Fig. 3) and compared to earlier work carried out with a Wild Leitz TAS Plus microscope-based image analysis system. The threshold values in the TAS images were set automatically. Particle separation filters were applied in the high concentration image but not in the low concentration image. 
Good agreement among the three analysis protocols was found in both the high and low concentration images. Figure 2.4 shows the size distributions obtained using the three programs for the images depicted in figure 2.3, plotted in both $\log -\log$ and semi-log form. Derived concentration values for the high concentration image are 2549, 3147 and 2449 ppm for the TAS, MOCHA and IPP analyses respectively and 1381, 1091 and 1462 ppm for the low concentration image. In both images, the TAS system shows better resolution of the small particles. This increased resolution results from the much higher magnification possible using a microscope with attached video camera. Based on comparisons with other methods and examination of calibration beads, the TAS system was determined to have a minimum resolution of $90 \mu \mathrm{m}$. Objects less than $90 \mu \mathrm{m}$ are visible on the film but below $90 \mu \mathrm{m}$ the size distribution curve becomes very steep, and deviates from the distribution for a sample collected at the same depth determined with an inverted microscope (Kranck et al., 1993). For the Photo-CD based analyses, the deviation of the curve occurs in the region of $125 \mu \mathrm{m}$. What is lost in resolution by using the Photo-CD method must be evaluated in terms of the time required to carry out each analysis. Processing a single image on the TAS system required almost 2 hours whereas size analysis in IPP required less than 15 minutes per image.

Because images are acquired from an approximately $40 \mathrm{~mm}$ thick focused zone, flocs can overlap at high concentrations resulting in overestimation of the size of these particles This effect can be partially compensated for by image enhancement and filtering. The 


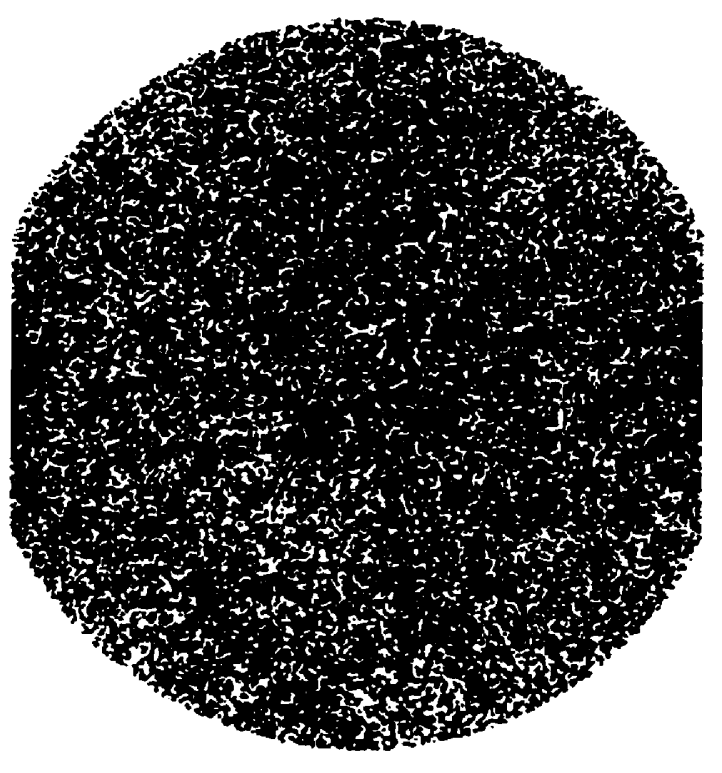

A

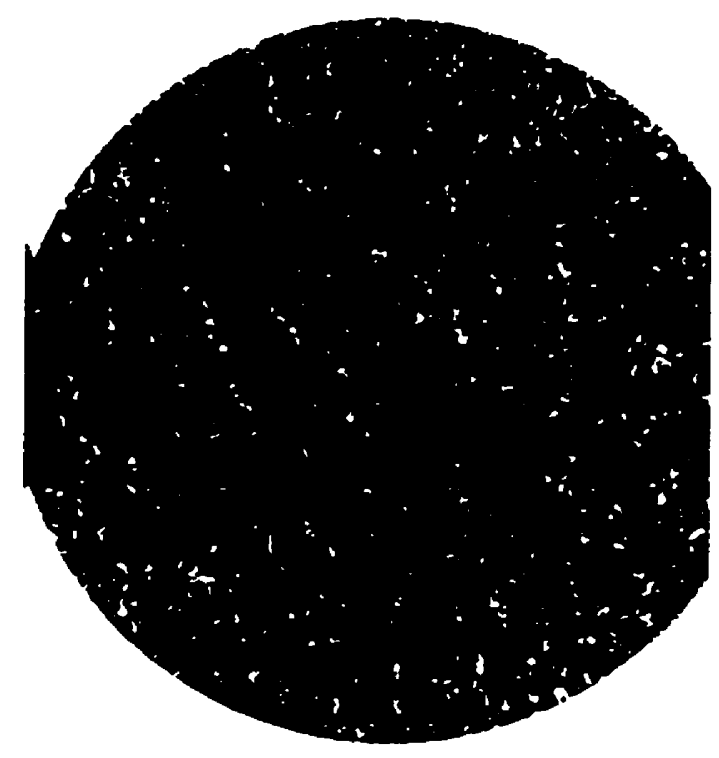

$\mathbf{B}$

Figure 2.3: Silhouette images from the Benthos 373 camera showing A: high concentration (218 $\left.\mathrm{mg} \mathrm{l}^{-1}\right)$ and B: low concentration (120 mg l-1) in situ samples from the Elbe Estuary mesocosm settling experiment (Milligan, 1995). 
High Concentration

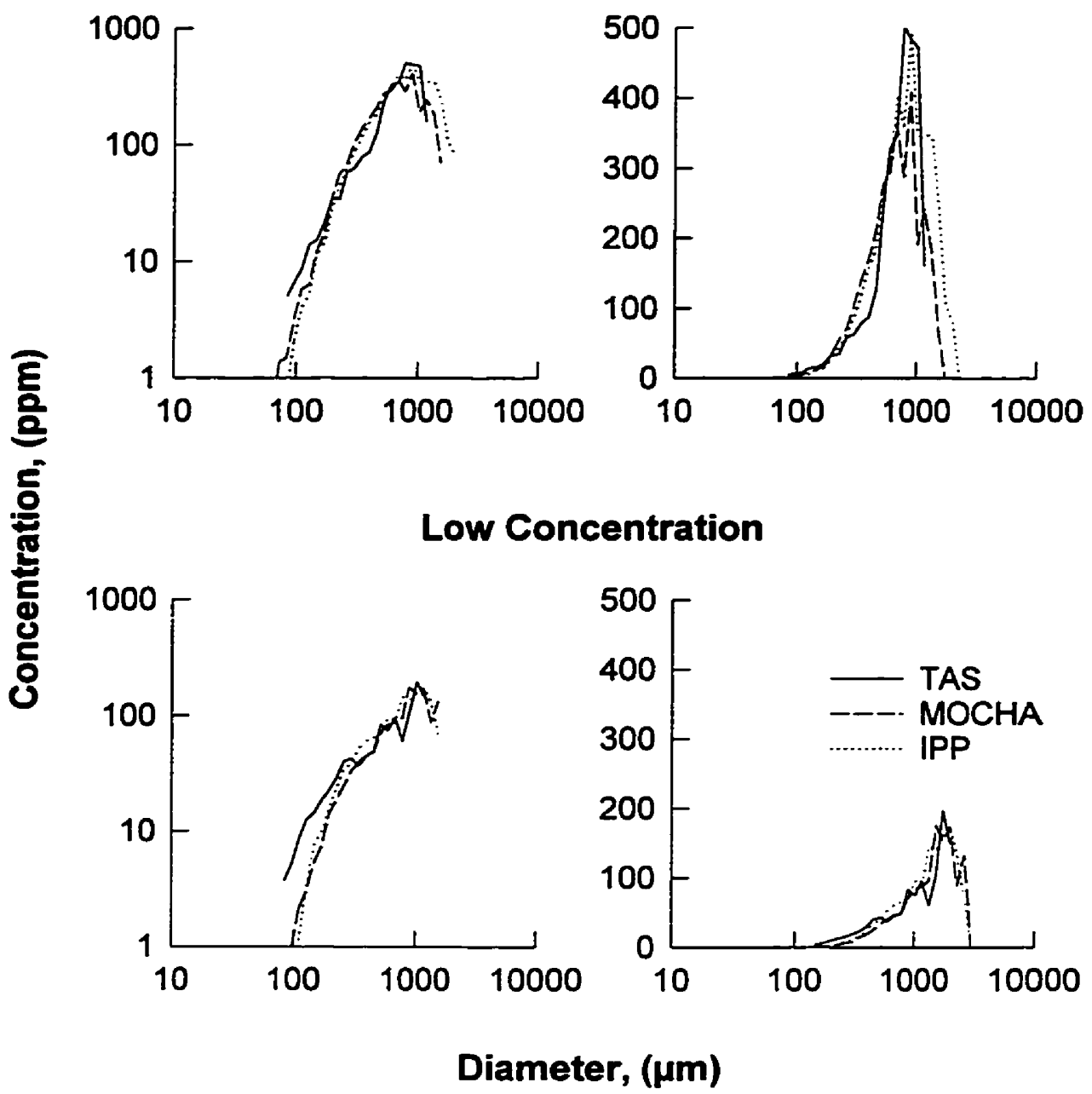

Figure 2.4: Particle size distributions for high and low concentration images depicted in figure 3 using TAS (solid line), MOCHA (dashed line) and IPP (dotted line) image analysis. Data plotted as both log-log and semi-log distributions. 
various filters available in image analysis programs can alter the size distribution drastically and must be applied with caution. One of the most difficult filters to apply is a particle separation filter due to its extreme effect on the size distribution (fig. 2.5). By applying an extreme separation, the size distribution becomes very smooth and total volume decreases due to under-detection of particle diameter (fig. 2.6). In the untreated image the size distribution and volume are overestimated because almost all aggregates in the field of view have touching pixels. The program MOCHA could not do a true particle separation due to its inability to track extinguishing particles on erosion. Hence the series of erosions and dilations used to separate objects resulted in the disappearance of small objects and elongate objects oriented at $45^{\circ}$ from vertical. Programs such as IPP which use Euclidean distance maps of pixel intensity to carry out the watershed filter avoid this problem (Russ, 1995). How much an image is subjected to enhancement is unfortunately in the hands of the operator. The number of iterations of the watershed filter applied to the image can be selected in IPP, limiting the degree to which particle separation occurs. To decrease error during analysis. a standard method of treatment before counting was established. As a result of the evaluation, IPP was selected to carry out the image analysis in the flocculation experiments. The control of the watershed algorithm was essential for the analysis of the high concentration samples in the study. In the image analysis carried out, 10 iterations of the IPP watershed algorithm were applied to each image before measurement. 


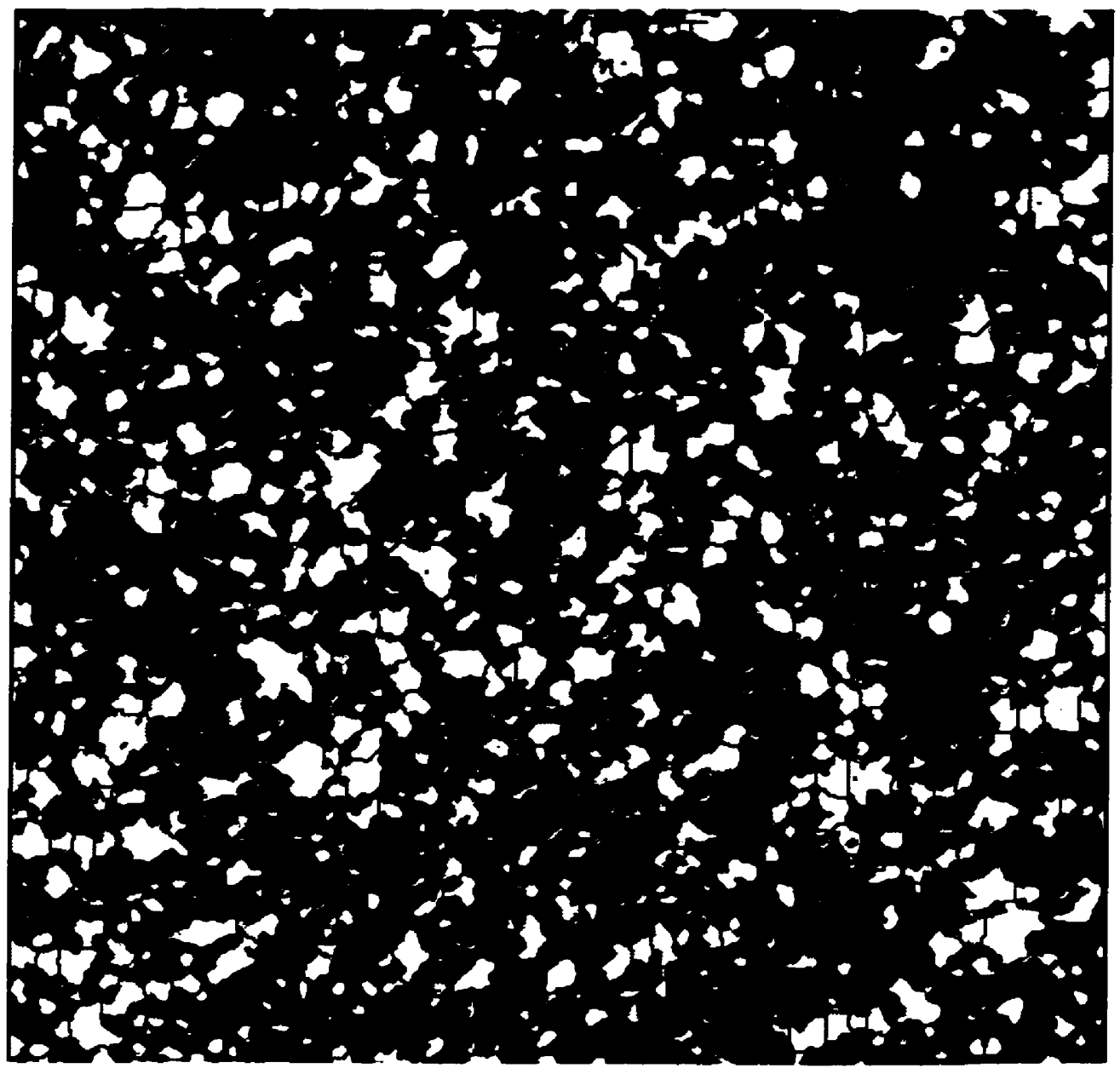

Figure 2.5: Magnification of a cropped section of the high concentration image depicted in fig.3a showing the effect of applying a watershed image to its maximum number of iterations. 


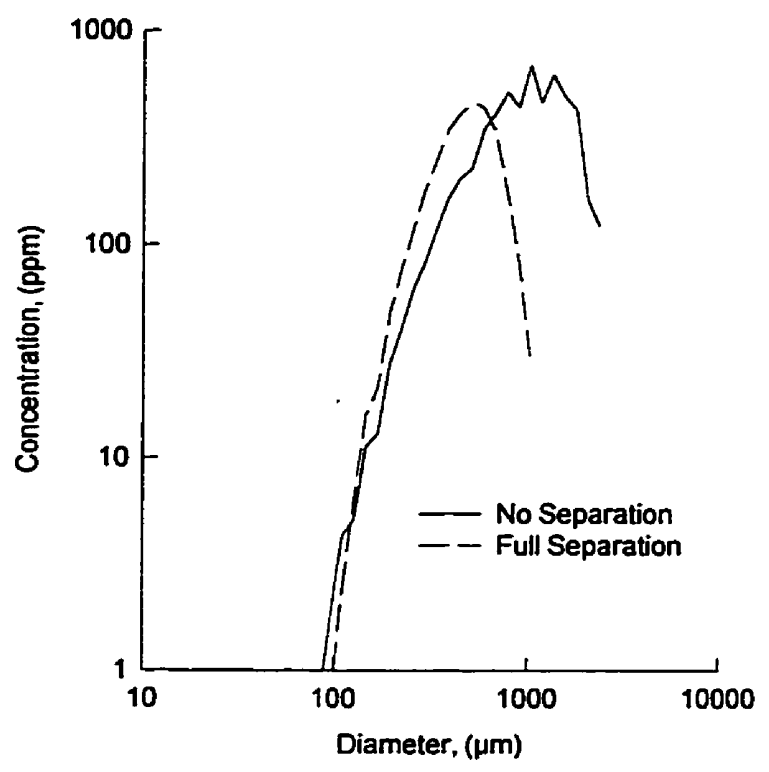

Figure 2.6: Particle size distributions for maximum watershed split image depicted in figure 5 (dotted line) and untreated image (solid line). 


\subsection{Materials:}

Three materials associated with discharges from offshore drilling operations were chosen for the experiment: bentonite, Silliker's clay, and used water-based drilling mud. A sample of dry mined bentonite, a principal component of the drill mud formulation used at the CoPan site, was obtained from the mud mixing floor of the drilling rig. Bentonite is an altered volcanic ash principally composed of montmorillonite, which is used in water based drill mud to increase viscosity and to prevent loss of fluid to the formation. Through osmotic swelling, montmorillonite can expand to several times its original volume in water (van Olphen, 1963). This expanding three layer clay also admits polar or ionic organic compounds between the unit layers to form organo-complexes (van Olphen, 1963). The disaggregated particle size spectra for bentonite shows a very high concentration of fine particle sizes, with a modal diameter $<1 \mu \mathrm{m}$ (Fig. 2.7). Silliker's clay is a glacio-marine clay, composed principally of kaolinite, a two layer clay, and illite, a non-expanding three layer clay, with an organic content $<0.13 \%$ dry weight (Kranck, 1980, 1986). The different bonding within the structure of the two layer kaolinite and the non expanding illite, prevent them from complexing with organics, hence these clays to a much larger extent flocculate as a result of collapse of the double layer in the saline suspension. The size spectrum for this material has a Rosin-Rammler size distribution consisting of a broad tail of fine particles and an exponential fall off at the coarse end, similar to that of materials obtained by crushing rock (Fig. 2.7) (Kranck, 1986). The bulk drill mud sample was taken from the inclined shaker discharge of the 


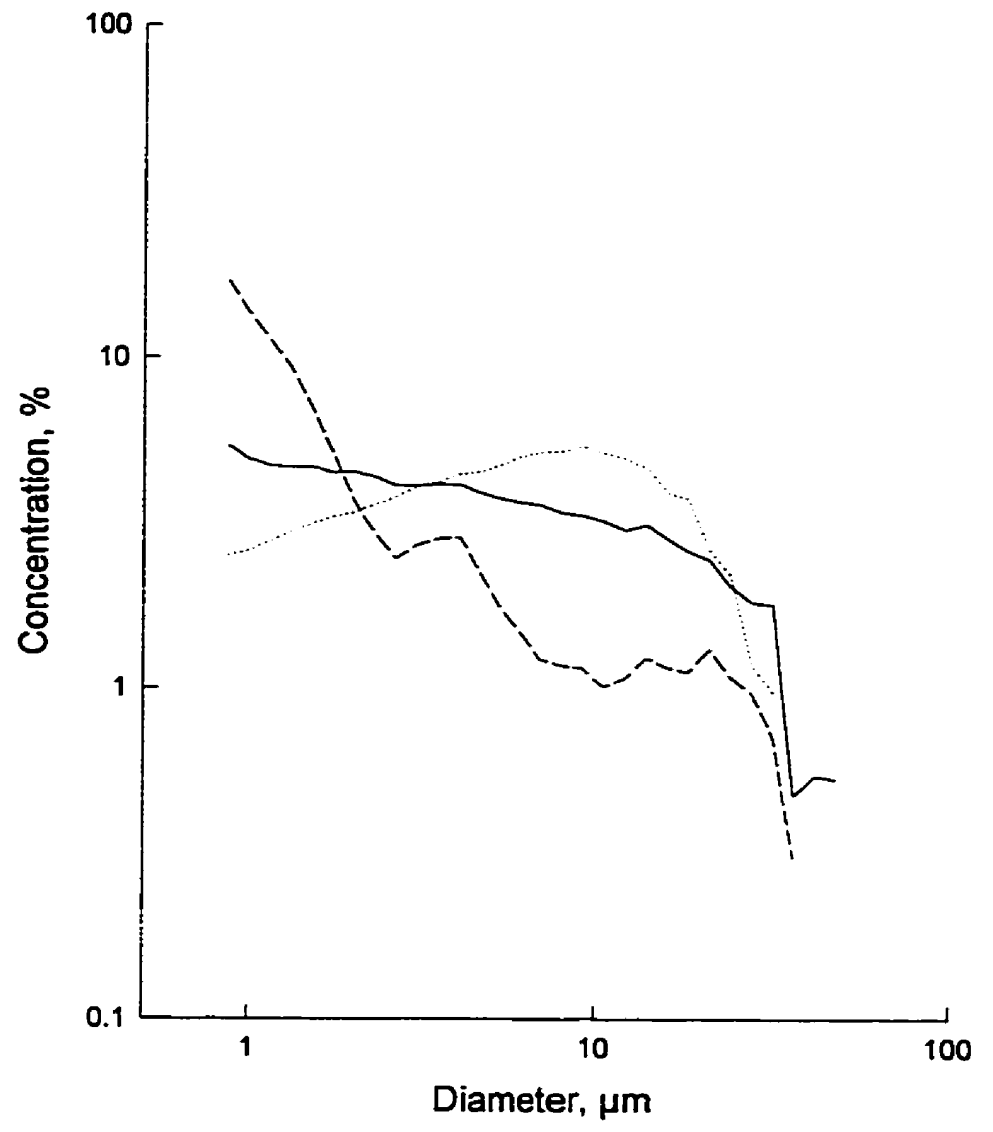

Figure 2.7: Disaggregated particle size spectra for bentonite (dashed line), Silliker's clay (dotted line) and drill mud (solid line). 
RGIII and consisted of expended water based gel mud, with high bentonite concentration but no barite, and cuttings ranging in size up to coarse sands. The mud sample used in the experiments had a size distribution intermediate between that of bentonite, dominated by fine particles sizes $<1 \mu \mathrm{m}$, and the broad Sillikers clay distribution (fig. 2.7). In addition, drill mud formulations contain varying amounts of organic material depending on the requirements for the section being drilled. Peanut shells and chicken feathers are two of the many possible components used to adjust the properties of the mud. No oil was associated with the section being drilled, either as part of the drilling fluid or from the formation, at the time of sampling (Muschenheim et al.,1995).

Two suspension concentrations were examined, $50 \mathrm{mg} \mathrm{l}^{-1}$ and $250 \mathrm{mg} \mathrm{l}^{-1}$. The low concentration treatments were of the same order as sediment concentrations found in the bottom $0.25 \mathrm{~m}$ of the BBL on George's and Sable Banks (Muschenheim et al., 1995, Milligan, unpubl. data), and the high concentration treatments were run at the maximum operational concentration for the camera.

Samples of bentonite and Silliker's clay were dry sieved at $63 \mu \mathrm{m}$ before weighing. Subsamples, 0.25 and $1.25 \mathrm{~g}$ for the low and high concentration treatments respectively, were weighed on a Mettler AE163 balance ( $0.1 \mathrm{mg}$ range) and placed in $20 \mathrm{ml}$ plastic vials. For the drill mud samples, reagent grade water was added to the used drilling muds to create a slurry. The dry weight concentration of particles $<63 \mu \mathrm{m}$ in the slurry was 
determined from 5 replicate subsamples of the slurry. Subsamples were weighed wet and then wet sieved at $63 \mu \mathrm{m}$ and dried before re-weighing to determine the concentration of material $<63 \mu \mathrm{m}$. Subsamples of the slurry were then weighed to give equivalent dry weight values of 0.25 and $1.25 \mathrm{~g}$ for the $<63 \mu \mathrm{m}$ fraction and placed in air tight vials and frozen.

\subsection{Flocculator:}

There were three major requirements in the design of the flocculator: one, particle size analysis had to be carried out without disturbing the material in suspension; two, aggregates formed had to be kept in suspension; and three, turbulence levels had to be of the same order as those found in nature. The first requirement was met by replacing the glass plates of the Benthos 373 camera with a glass-sided flocculation chamber. The flocculation chamber consisted of two $0.5 \mathrm{~cm}$ thick sheets of glass mounted in acrylic side panels giving an inside dimension of $120 \mathrm{~cm} \times 8.8 \mathrm{~cm} \times 4.5 \mathrm{~cm}(5.3 \mathrm{l})$. The flocculator was equipped with two swagelock fittings at one end to allow samples to be withdrawn through a glass tube and to allow the removal of bubbles introduced during filling. A 1-mm-diameter stainless steel wire was stretched between the two ends and was sealed using swagelock fittings to permit removal of the top plate for cleaning and filling of the column. In a manner similar to that of Tambo and Hozumi (1979) material was kept in suspension by rotating the column about its long axis so that the suspension was constantly settling. The column and camera were mounted on an aluminium frame which 
could be inverted at a selectable interval by means of a timer circuit connected to a control box which reversed the polarity of the DC motor driving the plate (fig. 2.8). Inversion of the column took $8.3 \mathrm{~s}$.

To satisfy the third requirement, a small plastic grid falling along a stainless steel wire stretched between the end caps of the column was used to generate turbulence. Oscillating grids have been the preferred method of replicating natural turbulence levels where a well-defined, homogeneous, isotropic field is required (e.g. Dickey and Mellor, 1980, Brumley and Jirka, 1987, Hill et al., 1992, Brunk et al., 1996). Three different grids were tested in the design of the flocculator. An initial flocculation experiment was carried out with no grid and a $100 \mathrm{mg} \mathrm{l}^{-1}$ suspension of drill mud with an inversion interval of 30 s. Flocs were observed in the column within approximately $1 \mathrm{~h}$ of introduction of the mud slurry. After 24 hours, visual inspection of the column showed an apparently uniform size of flocs in suspension with little or no material settling on the bottom of the column between inversions. Increasing the interval between inversions to $45 \mathrm{~s}$ and $60 \mathrm{~s}$ resulted in accumulations of drill mud flocs at the bottom of the column at $60 \mathrm{~s}$ but not at $45 \mathrm{~s}$.

A second experiment was conducted with drill mud at the same concentration and inversion rate but with a brass grid falling through the column. The grid was scaled down from that used by Dickey and Mellor (1980) to a $1 \mathrm{~cm}$ grid spacing with a solidity of 


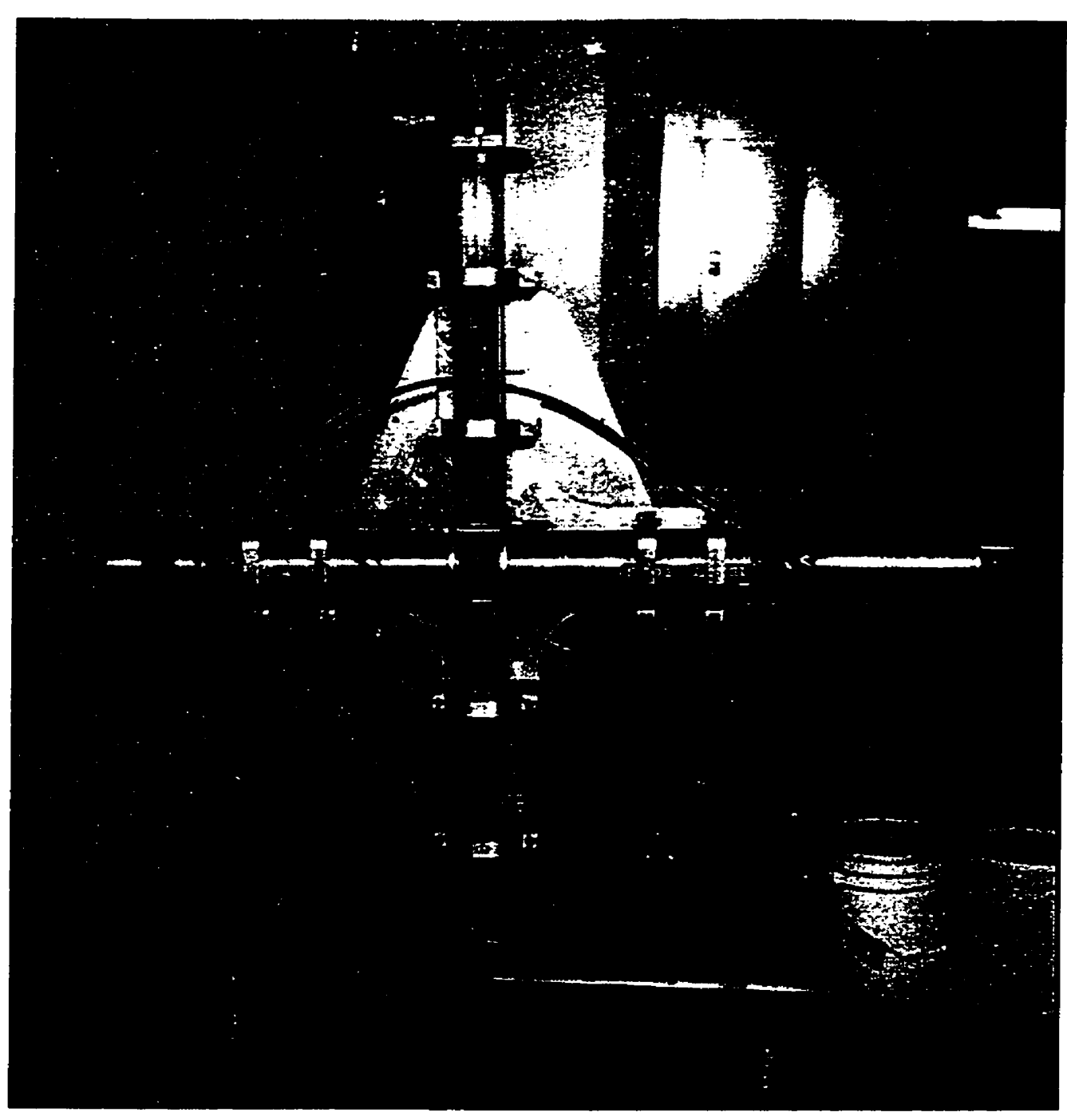

Figure 2.8: Camera and column flocculator in the vertical position. 
$20 \%$ which gave a settling speed of $30 \mathrm{~cm} \mathrm{~s}^{-1}$. No flocs were visible in the flocculator within $96 \mathrm{~h}$. Additional runs were made with the same concentration at inversion intervals of 45 and $60 \mathrm{~s}$ with the same result. The lack of visible aggregates in suspension in the grid stirred suspension was in marked contrast to the almost immediate visible flocculation of drill mud with no grid in the column. Similar tests with Sillikers clay resulted in no visible flocs being formed, even after as much as one week in the flocculator. After one grid-stirred run with drill mud in suspension, the column was stopped in the vertical position and the material in suspension was allowed to settle on the bottom overnight. Restarting the column resulted in a thick mat of flocculated drill mud being released as the column was inverted. Within two passes of the grid, however, the drill mud flocs in the column were disaggregated to a size below detection. A second set of tests were conducted using a grid with the same spacing and solidity constructed from PVC. The fall rate of the plastic grid was $10 \mathrm{~cm} \mathrm{~s}^{-1}$. Similar to the brass grid, no flocs were observed after periods of up to $96 \mathrm{~h}$ at inversion rates of 30,45 and $60 \mathrm{~s}$.

As a result of the experiments carried out with the $1 \mathrm{~cm}$ grid, the grid spacing was increased so that there would be fewer elements at which eddies would form. A very simple grid was constructed from two intersecting $0.3 \mathrm{~cm}$ thick plastic sheets, $7 \times 0.9 \mathrm{~cm}$ and $4 \times 0.9 \mathrm{~cm}$, giving a $23 \%$ solidity for the cross sectional area of the column. The intersecting plastic sheets were held by a $2 \mathrm{~cm}$ piece of threaded brass stock which was centre-drilled to allow the grid to run on the guide wire. The final weight of the grid in 
water was $20 \mathrm{~g}$, and it fell through the suspension at $20 \mathrm{~cm} \mathrm{~s}^{-1}$. Tests were run with 100 $\mathrm{mg} \mathrm{I}^{-1}$ drill mud at inversion intervals of 15,30 and $45 \mathrm{~s}$. Visible flocs were found for the $45 \mathrm{~s}$ inversion interval but not at the other two.

Based on the results of the preliminary tests (i.e. no visible flocs being formed after prolonged periods in the flocculator), it was obvious that the turbulence generated by the $1 \mathrm{~cm}$ grid could not be considered isotropic due to the very high shear rates generated at the grid elements and chamber walls. Isotropic turbulence occurs when turbulent kinetic energy production takes place at scales that are large relative to dissipation scales (Tennekes and Lumley, 1972). As energy cascades from large production scales to small dissipation scales, directionality is reduced, thereby leading to an isotropic turbulent field. With the small grid spacing, energy was introduced at a small scale, thus producing a heterogeneous distribution of kinetic energy which resulted in local regions of high shear. These high local shears exceeded the bond strength of the particles in suspension preventing the growth of aggregates to sizes within the analysis range. Although high shear is also found at the edges of the open plastic grid, the distance between elements results in greater separation in energy production and dissipation scales yielding a more even distribution of energy in the column. The greater isotropy and homogeneity of the turbulent energy field lessens the effect of localised, high shear regions on floc size. 
Characterisation of the energy dissipation in the flocculator using the method described by (e.g.) Dickey and Mellor (1980) for grid induced turbulence could not be applied in this situation due to the final design of the grid element. However, using a similar method to that for paddle flocculators (Tambo and Hozumi, 1979, Spicer and Pratsinis, 1996), power input to the column was used to calculate the average energy dissipation rate. Energy lost to the fluid in the column was estimated from the potential energy of the grid falling through the water in the column:

$$
\text { Potential Energy }=\text { Kinetic Energy }+ \text { Energy Dissipated }
$$

The kinetic energy generated within the system was less than 0.002 of the potential energy thus allowing the turbulent energy dissipation rate, $\varepsilon$, to be estimated from:

$$
\varepsilon=\frac{\mathrm{mgh}}{\rho t v}
$$

where $\mathrm{m}$ is the mass of the grid, $\mathrm{g}$ is the acceleration due to gravity, $\mathrm{h}$ the height of the column, $\rho$ is the density of the fluid, $t$ is the time over which the disturbance was applied, and $v$ is the volume of the suspension in the column. To conform with the majority of other experiments investigating the effect of turbulence on floc size, turbulent shear 
within the column was expressed as shear rate, $\mathrm{G}$, determined from the average dissipation energy within the column using the expression

$$
G=\left(\frac{\varepsilon}{v}\right)^{\frac{1}{2}}
$$

In equation (2), $v$ is the kinematic viscosity of the fluid in the column and $\varepsilon$ is the average turbulent energy dissipation rate (Spicer and Pratsinis, 1996). Two possible values for $t$ could be used the calculation of $\mathrm{G}$ : the time required for the grid to fall through the column $(8.3 \mathrm{~s})$ or the sum of fall time and the interval between inversions $(53.3 \mathrm{~s})$. The former assumes that energy was immediately dissipated after the passage of the grid and the latter assumes that the energy was dissipated over the period between each inversion. Assuming negligible frictional loss from the grid to the guide wire and using the viscosity for sea water at $20^{\circ} \mathrm{C}$ and a salinity of $30 \mathrm{psu}$, gave shear rates from $8-20 \mathrm{~s}^{-1}$ over the range of possible dissipation times. Shears of this order have been calculated for Sable Island Bank from a current meter mooring $1 \mathrm{~m}$ above the bottom (Muschenheim et al., 1995a). Energy dissipation would be expected to vary within the column with much higher shear rates near the grid in a region somewhat analogous to the boundary condition in high flow regions.

\subsection{Experimental design and procedures:}

An orthogonal analysis was used to determine the significance of the three factors on maximal floc size. The block design consisted of three replicate treatments of the factors: 
turbulence (grid off, 0, and grid on, 1), composition (bentonite, B, Sillikers clay, S, and drill mud, M), and concentration (250 $\mathrm{mg} \mathrm{l}^{-1}, 50 \mathrm{mg} \mathrm{l}^{-1}$ ). Treatments were randomly selected by withdrawing one of the pre-weighed samples labelled with the treatment conditions from a bag. The dependent variables were maximal floc size, determined from the in situ particle size distribution of the suspension after 20 hours of shear and the median settling velocity calculated from samples withdrawn during still water settling of the suspension at the end of the treatment.

The pre-weighed samples were dispersed in $20 \mathrm{ml}$ reagent grade water and disaggregated in an ultrasonic bath for 5 minutes. The bentonite and clay samples were added directly to the flocculator and the drill mud samples were wet screened at $63 \mu \mathrm{m}$ with the suspension medium just prior to placing them in the column. Similar to previous studies of drill mud flocculation, $0.45 \mu \mathrm{m}$ filtered sea water (mean $30.4 \mathrm{psu}, \mathrm{SD} 0.2$ ) was used as the suspension medium (Muschenheim et al., 1989). To prevent out-gassing within the flocculator, the seawater was held at room temperature for 24 hours (mean $21.6^{\circ} \mathrm{C}$ SD 1.3). For turbulent treatments the grid was placed in the column. After adding the sample the suspension was vigorously mixed by partially filling the column and then inverting it several times before adding an additional $500 \mathrm{ml}$ of seawater and removing all bubbles. The column was then continuously inverted for 5 minutes before withdrawing a sample for bacterial analysis and replacing the volume removed. The motor controller was set to invert the column after $45 \mathrm{~s}$ in the vertical position based on earlier trial runs. A series of 
initial images were taken with the camera and the column was left to run overnight. After approximately 20 hours, pictures were taken of the suspension with the column rotating. The column was then stopped in the vertical position and a sample was withdrawn using a syringe connected to a $3 \mathrm{~mm}$ diameter glass tube inserted through the top of the flocculator to a depth of $15 \mathrm{~cm}$. Initial samples for bacteria and disaggregated particle size distribution analysis were withdrawn within $15 \mathrm{~s}$ of stopping the column. Additional samples for volume analysis were withdrawn at $2.8,5.37,11.25,22.5,45$ and 90 minutes during the settling of the suspension in the column. The volume concentration in each sample was determined from the disaggregated particle size distribution using a Coulter Multisizer (Milligan and Kranck, 1991). Two apertures, $30 \mu \mathrm{m}$ and $200 \mu \mathrm{m}$, were used to define the particle size spectrum from $0.79 \mu \mathrm{m}$ to $100 \mu \mathrm{m}$ using a $1 / 5 \phi \mathrm{mid}$ point diameter class interval. The total volume was determined from the sum of the volume in each size class over the range analysed.

For the bacterial analysis, $2 \mathrm{ml}$ subsamples were fixed with $2 \%$ para-formaldehyde and stored until analysis at $-70^{\circ} \mathrm{C}$. Concentrations were obtained with a Beckman FACS flow cytometer using the techniques developed by Jellet et al., (1996). The bentonite clay samples could not be counted accurately due to interference with the staining techniques used. 


\subsection{Data reduction and analysis:}

\subsection{1 in situ particle size}

The volume data obtained for each image were binned on a $1 / 3 \phi$ mid-point diameter class interval in which volume doubles in each subsequent size class (Milligan and Kranck, 1991). Results were plotted as smoothed histograms of log concentration, normalised for the area analysed, as a function of log diameter (fig. 9). Tests run on the size -spectra showed that some of the distributions were not log-normally distributed which eliminated the use of either mean diameter or mean diameter plus two standard deviations to describe the maximal floc size, as suggested by Berhane et al., (in press). Because the main interest of this study was maximal floc size, the 25th percentile for the cumulative volume $\left(D_{25}\right)$, determined by summing the volume of all objects sized in the image analysis, was used to describe the size distribution for each treatment (Folk, 1980). No significant difference $(p<0.01)$ was found on the overall results of the experiment using either modal diameter or $D_{50} . D_{25}$ values for the final floc population in suspension are given in table 1 .

In the high concentration turbulent Sillikers clay sample, the concentration of flocs and dispersed clay was too great for image analysis to be carried out. Visual inspection of the negatives revealed a very high concentration of small flocs on a dark background. The 
high concentration of small flocs and dispersed clay resulted in over-detection for these images during image analysis so individual flocs could not be measured. For the replicates in these treatments, a D25 value of $125 \mu \mathrm{m}$, the minimum resolution of the camera and photo-CD digitisation method used, was assigned for use in the ANOVA. A maximal floc size of $125 \mu \mathrm{m}$ is likely a conservative estimate for Silliker's clay and was chosen to conform to the proposal of Burban et al. (1989) with respect to concentration effects on floc size. The effect of using an arbitrary value for D25 in the high concentration turbulent case for Sillikers clay was examined by substituting two other values in the ANOVA: $12 \mu \mathrm{m}$, the D25 value for disaggregated Silliker's clay, and 238 $\mu \mathrm{m}$, the value from the low concentration treatment.

\subsubsection{Settling velocity}

The settling velocity of the material in suspension after 20 hours was calculated using the method of Owen (1976) for determining the settling velocities of cohesive muds. In the place of the bottom withdrawal method of Owen (1976), samples were collected at a depth of $0.15 \mathrm{~m}$ as suggested by Allersma (1980). The median settling velocity, $\left(w_{50}\right)$, for the material in suspension after $20 \mathrm{~h}$ was calculated from plots of the percentage volume of material in suspension, determined from the Coulter analysis, against time using the graphical method described by Owen (1976) (Table 2.1). 


\begin{tabular}{|c|c|c|c|c|}
\hline Concentration & Composition & Turbulence & $D_{25}(\mu \mathrm{m})$ & $w_{s 0}\left(\mathrm{~cm} \mathrm{~s}^{-1}\right)$ \\
\hline 50 & $\overline{\mathrm{B}}$ & $\overline{0}$ & 939 & 0.026 \\
\hline 50 & B & 0 & 1195 & 0.050 \\
\hline 50 & B & 0 & 1092 & 0.031 \\
\hline 50 & B & 1 & 252 & 0.003 \\
\hline 50 & B & 1 & 288 & 0.004 \\
\hline 50 & B & 1 & 263 & 0.003 \\
\hline 250 & B & 0 & 925 & 0.025 \\
\hline 250 & B & 0 & 816 & 0.028 \\
\hline 250 & B & 0 & 960 & 0.017 \\
\hline 250 & B & 1 & 278 & 0.012 \\
\hline 250 & B & 1 & 422 & 0.018 \\
\hline 250 & B & 1 & 354 & 0.021 \\
\hline 50 & $S$ & 0 & 312 & 0.109 \\
\hline 50 & $\mathbf{S}$ & 0 & 392 & 0.147 \\
\hline 50 & $\mathbf{S}$ & 0 & 446 & 0.143 \\
\hline 50 & $\mathbf{S}$ & 1 & 215 & 0.028 \\
\hline 50 & $\mathbf{S}$ & 1 & 243 & 0.109 \\
\hline 50 & $\mathbf{S}$ & 1 & 257 & 0.050 \\
\hline 250 & $\mathbf{S}$ & 0 & 363 & 0.027 \\
\hline 250 & $\mathbf{S}$ & 0 & 380 & 0.038 \\
\hline 250 & S & 0 & 480 & 0.192 \\
\hline 250 & $\mathbf{S}$ & 1 & (125) & 0.007 \\
\hline 250 & S & 1 & $(125)$ & 0.016 \\
\hline 250 & S & 1 & (125) & 0.010 \\
\hline 50 & $\mathbf{M}$ & 0 & 623 & 0.472 \\
\hline 50 & $\mathbf{M}$ & 0 & 506 & 0.379 \\
\hline 50 & $\mathbf{M}$ & 0 & 666 & 0.439 \\
\hline 50 & $\mathbf{M}$ & 1 & 387 & 0.031 \\
\hline 50 & $M$ & 1 & 354 & 0.038 \\
\hline 50 & $\mathbf{M}$ & 1 & 340 & 0.046 \\
\hline 250 & $\mathbf{M}$ & 0 & 857 & 0.543 \\
\hline 250 & $\mathbf{M}$ & 0 & 926 & 0.472 \\
\hline 250 & $\mathbf{M}$ & 0 & 757 & 0.446 \\
\hline 250 & $\mathbf{M}$ & 1 & 524 & 0.089 \\
\hline 250 & $\mathbf{M}$ & 1 & 506 & 0.083 \\
\hline 250 & $\mathbf{M}$ & 1 & 491 & 0.058 \\
\hline
\end{tabular}

Table 2.1: Listing of concentration (mg I $\mathrm{I}^{-1}$ ), composition (Bentonite, B, Silliker's clay, $\mathrm{S}$, and drill mud, $M)$, turbulence (grid off, 0 , grid on, 1$)$, maximal floc size $\left(D_{25}\right)$ and settling velocity $\left(w_{50}\right)$. 
2.6.3 Statistical analysis.

To evaluate the factors influencing maximal floc size, a fully factorial multiple analysis of variance (ANOVA) was applied in SYSTAT v. 5.0 to the data block of 36 treatment combinations with turbulence, composition and concentration as factors and $D_{25}$ as the variable (Wilkinson et al., 1992). A second ANOVA with the log transformed values of $w_{50}$ as the variable was used to examine the effects on particle settling behaviour and a third ANOVA was run with the $D_{25}$ and the bacterial counts from the Silliker's clay and drill mud treatments to determine the influence of bacterial concentration on maximal floc size. A pairwise comparison of the factors was applied using a Tukey post hoc test to determine significant interactions between the treatments (Day and Quinn, 1989, Wilkinson et al., 1992). 


\section{CHAPTER 3:}

\section{Maximal Floc Size:}

Of the three factors examined, highly significant effects on maximal floc size were found for turbulence and composition but no significant effect for concentration was seen in this experiment (Table 3.1). The pronounced effect of turbulence on the size distribution found in the ANOVA is obvious in the size spectra (Fig. 3.1). In all cases, the size distribution for the turbulent samples was offset to smaller sizes. Size distributions showing self similarity due to floc break-up as suggested by Kranck (1990) and Spicer and Pratsinis (1996) were found for the materials at the different turbulence levels. The fact that all samples analysed showed well sorted size distributions supports the assumption of Hill (1996) that aggregates break into large fragments rather than undergoing complete dispersion. The smallest visible flocs were in the turbulent samples whereas large individual flocs with little un-aggregated material were seen in the nonturbulent cases. The no-grid condition exhibited some turbulence which could be seen by the movement of the flocs in the column. Much of this self-generated turbulence appeared to be the result of floc settling which in the case of the drill mud was very rapid.

Composition had a highly significant effect on maximal floc size (Table 3.1). The result of varying composition in the suspension can be observed in the size spectra which show the largest flocs to be formed in the non-turbulent bentonite samples $(>1000 \mu \mathrm{m})$ and the smallest with Silliker's $(<500 \mu \mathrm{m})$ (Fig.3.1, Table 2.1). In all treatments, excluding the 
high concentration turbulent case, maximal floc size for the Silliker's clay was less than the other two materials under the same conditions.

ANALYSIS OF VARIANCE FOR $D_{25}$

\begin{tabular}{|cccccc||}
\hline Source & Sum of Squares & Deg. Freedom & Mean Square & F-Ratio & p \\
Turbulence & 1394761.00 & 1 & 1394761.00 & 323.777 & 0.000 \\
Composition & 873809.06 & 2 & 436904.53 & 101.422 & 0.000 \\
Concentration & 11520.44 & 1 & 11520.44 & 2.674 & 0.115 \\
Turb. \& Comp. & 373095.50 & 2 & 186547.75 & 43.305 & 0.000 \\
Turb. \& Conc. & 93.44 & 1 & 93.44 & 0.022 & 0.884 \\
Comp.\&Conc. & 117695.39 & 2 & 58847.69 & 13.661 & 0.000 \\
All Factors & 72054.06 & 2 & 36027.03 & 8.363 & 0.002 \\
ERROR & 103386.67 & 24 & 4307.78 & & \\
\hline
\end{tabular}

Table 3.1: Results from ANOVA showing effects of the factors turbulence, (grid, no grid), composition (bentonite, Sillikers clay, drill-mud), and concentration (low, high), on the variable maximal floc size, $\left(D_{25}\right)$, for three replicate treatments (table 2.1).

RESULTS OF TUKEY POST HOC PAIRWISE ANALYSIS FOR $D_{25}$

\begin{tabular}{|c|c|c|c|c|c|c|c|c|c|c|c|c|}
\hline $\begin{array}{l}\text { Treatment } \\
250 \text { S } 0\end{array}$ & $\begin{array}{c}250 \mathrm{S0} \\
1.000\end{array}$ & $\overline{250 \mathrm{SI}}$ & $\overline{50 \mathrm{SO}}$ & $\overline{50 \overline{\mathrm{i}}}$ & $\overline{250 \mathrm{~B} 0}$ & $250 \mathrm{~B} \mathrm{I}$ & $50 \mathrm{BO}$ & $\overline{50 \mathrm{~B} \mathrm{I}}$ & $250 \mathrm{MO}$ & $\overline{250 \mathrm{M}}$ & $\overline{50 \mathrm{M} 0}$ & $50 \mathrm{M} \mathrm{I}$ \\
\hline $250 \mathrm{~S} \mathrm{I}$ & 0.001 & 1.000 & & & & & & & & & & \\
\hline $50 \mathrm{S0}$ & 1.000 & 0.003 & 1.000 & & & & & & & & & \\
\hline $50 \mathrm{~S} \mathrm{I}$ & 0.125 & 0.618 & 0.281 & 1.000 & & & & & & & & \\
\hline 250 B 0 & 0.000 & 0.000 & 0.000 & 0.000 & 1.000 & & & & & & & \\
\hline $250 \mathrm{~B} 1$ & 0.994 & 0.013 & 1.000 & 0.622 & 0.000 & 1.000 & & & & & & \\
\hline 50 B 0 & 0.000 & 0.000 & 0.000 & 0.000 & 0.102 & 0.000 & 1.000 & & & & & \\
\hline $50 \mathrm{~B} \mathrm{I}$ & 0.326 & 0.302 & 0.591 & 1.000 & 0.000 & 0.907 & 0.000 & 1.000 & & & & \\
\hline $250 \mathrm{M} 0$ & 0.000 & 0.000 & 0.000 & 0.000 & 0.996 & 0.000 & 0.011 & 0.000 & 1.000 & & & \\
\hline $250 \mathrm{M} 1$ & 0.774 & 0.000 & 0.498 & 0.002 & 0.000 & $0.20 \mathrm{I}$ & 0.000 & 0.007 & 0.000 & 1.000 & & \\
\hline $50 \mathrm{MO}$ & 0.055 & 0.000 & 0.020 & 0.000 & 0.001 & 0.005 & 0.000 & 0.000 & 0.005 & 0.850 & 1.000 & \\
\hline $50 \mathrm{M} \mathrm{I}$ & 0.999 & 0.009 & 1.000 & 0.517 & 0.000 & 1.000 & 0.000 & 0.838 & 0.000 & 0.267 & 0.008 & 1.000 \\
\hline
\end{tabular}

Table 3.2: Levels of significance for interactions between concentration (low, $50 \mathrm{mg} \mathrm{l}^{-1}$, high, $250 \mathrm{mg} \mathrm{l}^{-1}$ ), composition (bentonite, B, Sillikers clay, S, drill-mud, $M$ ) and turbulence (grid off, 0 , grid on, 1 ), on the variable maximal floc size, $\left(D_{2 s}\right)$, using Tukey post hoc analysis. 


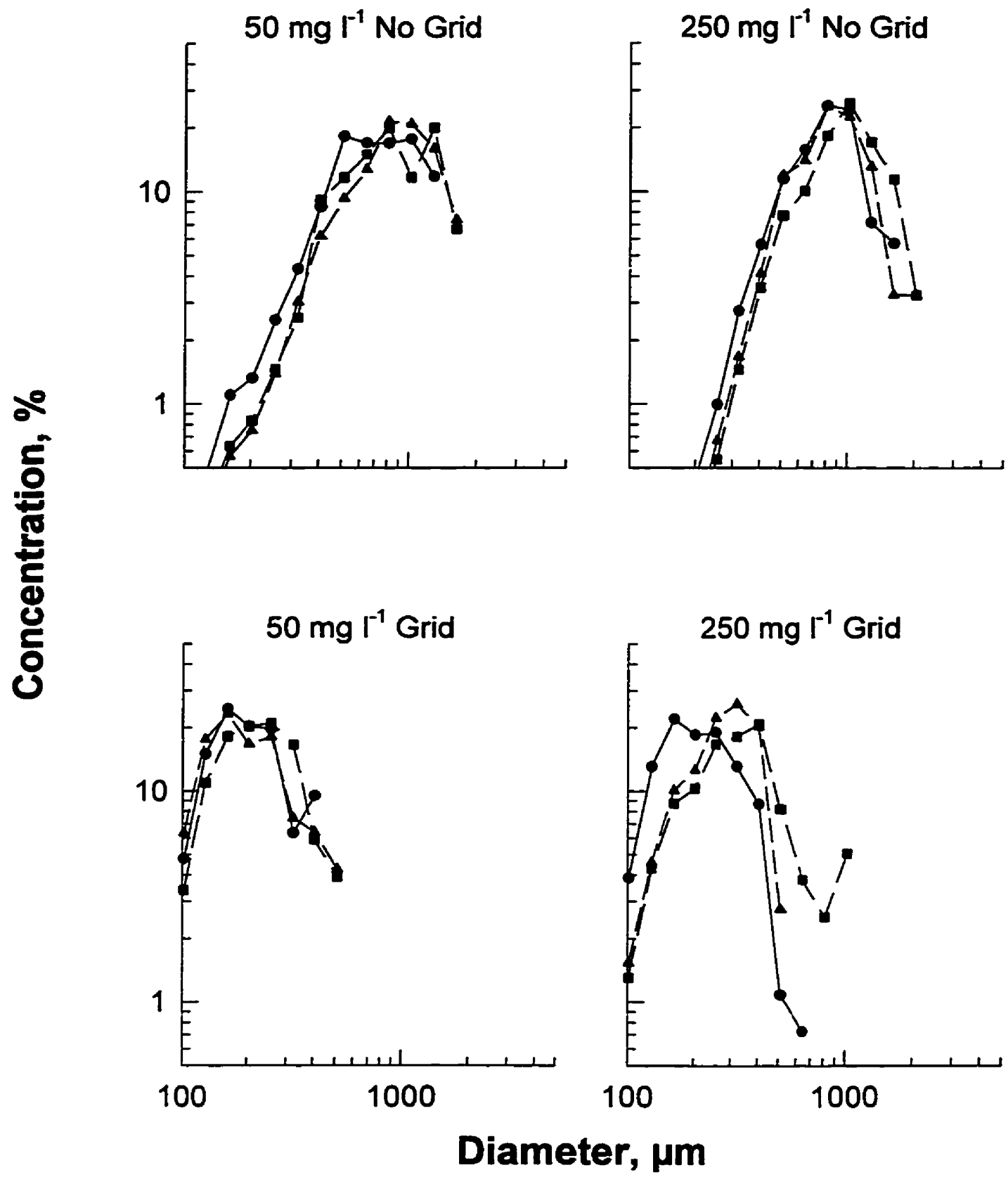

Figure 3. la: Log-log plots of concentration vs diameter from image analysis of flocculated suspensions of bentonite. Symbols and lines represent replicates. 


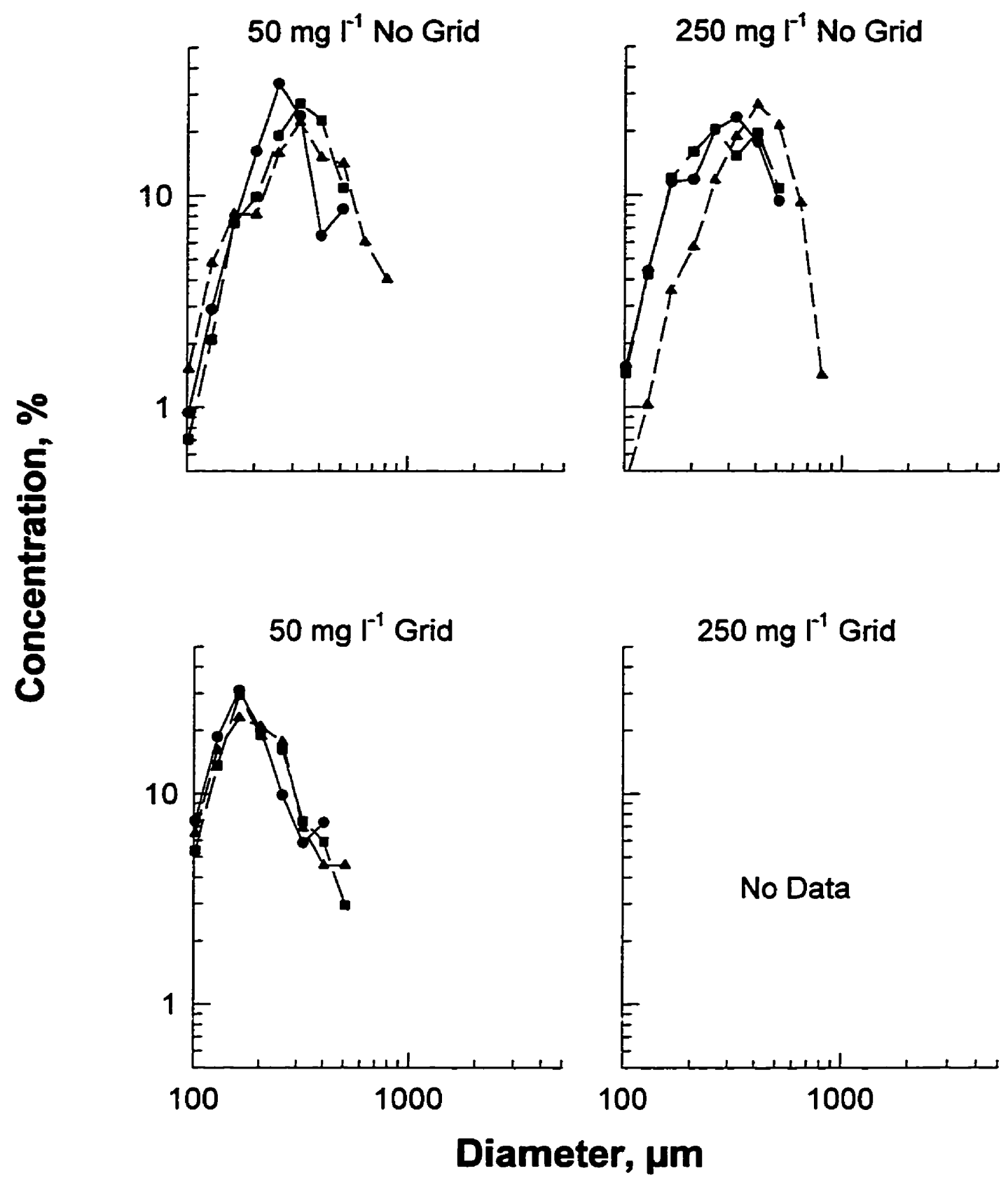

Figure 3.1b: Log-log plots of concentration vs diameter from image analysis of flocculated suspensions of Silliker's clay. Symbols and lines represent replicates. 


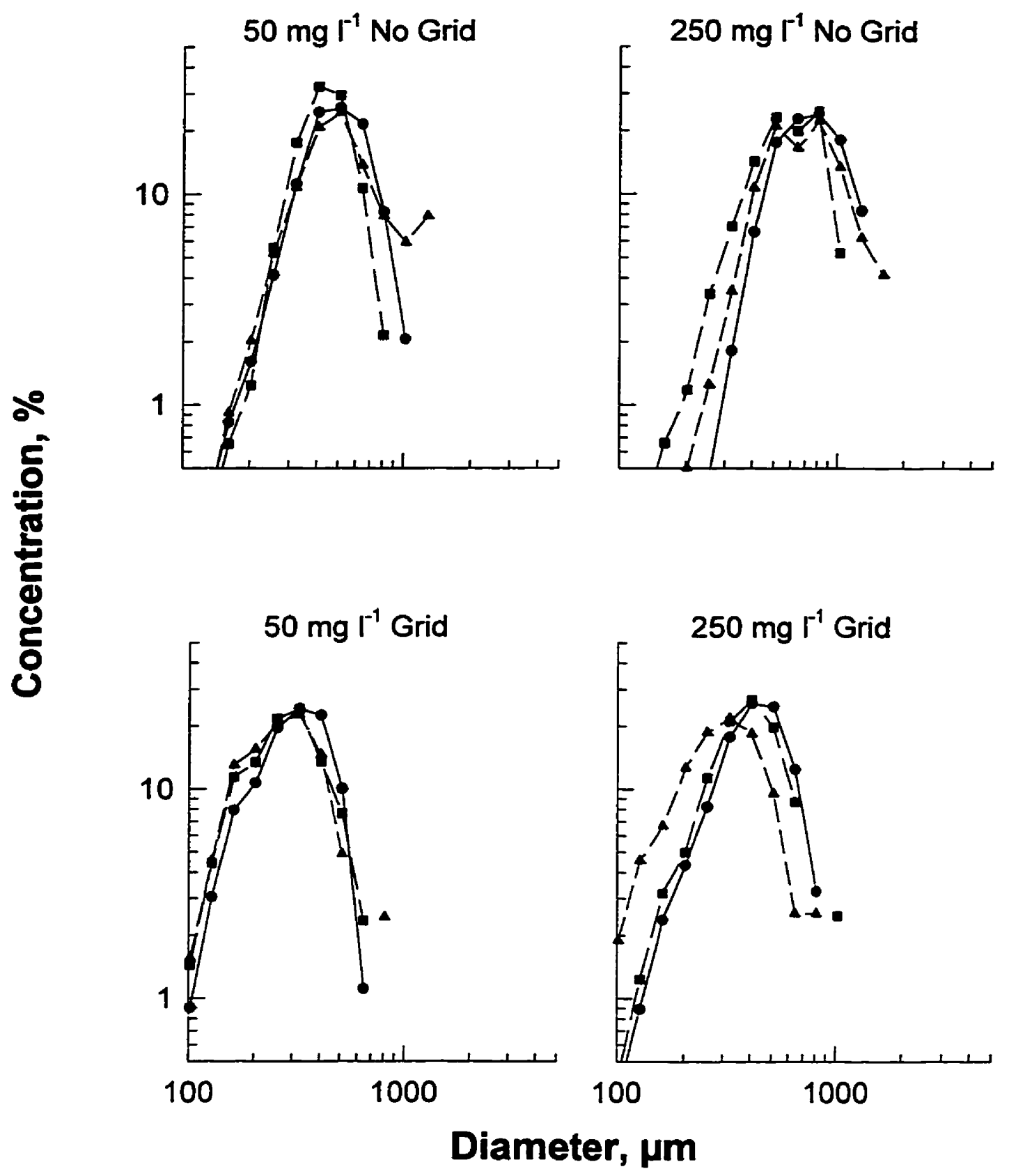

Figure 3.1 c: Log-log plots of concentration vs diameter from image analysis of flocculated suspensions of drill mud. Symbols and lines represent replicates. 
No significant effect from bacteria concentration was found over the 20 hours of the experiment runs. Initial and final bacteria counts were higher in the high concentration used drill-mud samples $\left(5.1 \times 10^{5}\right)$ than the Sillikers clay $\left(2.1 \times 10^{5}\right)$ and low concentration drill-mud samples $\left(3.0 \times 10^{5}\right)$. Initial counts were of the same order as those reported by Muschenheim et al., (1989) for glacial till in $0.45 \mu \mathrm{m}$ filtered seawater but did not increase to the same levels at the end of 20 hours, possibly as a result of the column being a closed system opposed to the open channel flume used by Muschenheim et al. (1989). An ANOVA carried out with the results from the bacterial analyses for the Sillikers and drill-mud samples showed no significant effect on maximal floc size indicating that composition effects could not be attributed to the suspension medium.

No overall effect of varying the concentration of the treatment was seen on maximum floc size (Table 3.1). To examine the effect of the dummy value entered for the high concentration turbulent Sillikers case, the ANOVA and post hoc tests were also run using $12 \mu \mathrm{m}$ and $238 \mu \mathrm{m}$ for $D_{25}$. Entering these values for the missing data resulted in a significance being detected for concentration in the overall ANOVA when $238 \mu \mathrm{m}$ was substituted, suggesting a positive correlation between concentration and maximal size. A significant negative effect for concentration could only be detected for the high concentration Sillikers sample when unrealistically small $D_{25}$ values were substituted. Significant differences in $D_{25}$ values were found only in the non-turbulent drill mud sample where the $D_{25}$ values were greater for the high concentration sample. 
Examination of the spectra and the results of the ANOVA shows a significant interaction between turbulence and composition. Pairwise comparisons carried out in the post hoc analysis show that the type of material in suspension will control the degree to which the flocs disaggregate when turbulent shear is applied (table 3.2). Bentonite flocs were larger in low turbulence than other compositions and showed much greater disaggregation when the grid was introduced to the column than did those formed with drill mud. Sillikers clay flocs were small under all conditions. The maximum diameters achieved for Sillikers under low turbulence were not significantly different from those of drill mud under turbulent conditions.

The effect of turbulence on maximal floc size was not influenced by varying the concentration in these experiments (table 3.1). Pairings in the post hoc analysis showed similar results to those for turbulence alone with non-turbulent maximal diameters being greater than turbulent diameters at both high and low concentrations. A significant effect was reported for the interaction of composition with concentration. However, examination of the post hoc results also shows that concentration is not a major factor in the interaction but rather is dominated by the effect from composition. The levels of significance reported in the interaction comparisons are the same in almost all cases as those for composition alone. Exceptions were found for the high concentration drill mud and the assigned value for Sillikers clay which became significant when replaced with the 
$\mathrm{D}_{25}$ value for the low concentration case. Although these results would indicate a slightly positive effect from concentration, the use of the assigned value for Sillikers would suggest that at best, concentration has a neutral effect on floc size in combination with composition.

Particles in suspension in the column were subjected to both shear and differential settling aggregation mechanisms (Johnson et al., 1990). It would appear that by increasing the time between inversions, the material in suspension had a longer period to form aggregates by differential settling. This enhanced aggregation likely shifted the balance between aggregation and disaggregation in favour of floc formation. The variation in the size and stability of the flocs grown in this experiment suggests that bonding strength is an inherent property of the material in suspension that should be examined in the context of turbulence when modelling the flocculation of a suspension. 


\section{CHAPTER 4:}

\section{Settling Velocity}

Results from the still water settling of the suspensions showed the same relationship as that between maximal floc size and the factors tested. An ANOVA carried out with the $\log$ transformed $w_{50}$ values and the three factors tested found highly significant effects for turbulence and composition but no overall effect from concentration (table 4.1). In most cases the $\mathrm{w}_{50}$ of the turbulent samples was less than that for the non-turbulent conditions, in agreement with the results of the maximal floc size analysis (table 2.1). In the case of the high concentration bentonite, no significant difference was found for turbulence (table 4.2), suggesting that flocs may form rapidly after cessation of grid stirring. Although composition was found to have a significant effect on settling velocity, examination of the post hoc paired comparisons, shows that there were no significant differences between the two clays tested (table 4.2). No overall effect was found for concentration but significant effects were detected for concentration and composition together. Concentration effects were only seen in the turbulent cases for bentonite, where the settling velocity of the high concentration sample was greater than that of the low, and for Sillikers clay where the opposite was observed (table 2.1). The lack of significant effects found for concentration alone suggests that the significance found for concentration in combination with composition results from the type of material in suspension. No significant effects were found for turbulence in combination with concentration or composition but a significant effect was found for the interaction of all three factors. 
ANALYSIS OF VARIANCE FOR W

\begin{tabular}{|cccccc|}
\hline Source & Sum of Squares & Deg. Freedom & Mean Square & F-Ratio & p \\
Turbulence & 4.138 & 1 & 4.318 & 129.34 & 0.000 \\
Composition & 6.452 & 2 & 3.226 & 96.55 & 0.000 \\
Concentration & 0.011 & 1 & 0.011 & 0.32 & 0.576 \\
Turb. \& Comp. & 0.253 & 2 & 0.127 & 3.79 & 0.037 \\
Turb. \& Conc. & 0.141 & 1 & 0.141 & 4.23 & 0.051 \\
Comp.\&Conc. & 1.144 & 2 & 0.572 & 17.12 & 0.000 \\
All Factors & 0.575 & 2 & 0.287 & 8.60 & 0.002 \\
ERROR & 0.802 & 24 & 0.033 & & \\
\hline
\end{tabular}

Table 4.1: Results from ANOVA showing effects of the factors turbulence, (grid, no grid), composition (bentonite, Sillikers clay, drill-mud), and concentration (low, high), on the variable settling velocity, $\left(w_{s_{0}}\right)$, for three replicate treatments (table I).

RESULTS OF TUKEY POST HOC PAIRWISE ANALYSIS FOR w $_{50}$

\begin{tabular}{|c|c|c|c|c|c|c|c|c|c|c|c|}
\hline Treatment & $250 \mathrm{~S}$ & $250 \mathrm{~S}$ & 5050 & $50 \mathrm{~S}$ & $250 \mathrm{~B}$ & $250 \mathrm{E}$ & $50 \mathrm{~B}$ & B & $\mathbf{M}$ & 250 & $50 \mathrm{Ml}$ \\
\hline $250 \mathrm{~S} 0$ & 1.000 & & & & & & & & & & \\
\hline $250 \mathrm{~S} 1$ & 0.002 & 1.000 & & & & & & & & & \\
\hline $50 \mathrm{SO}$ & 0.459 & 0.000 & 1.000 & & & & & & & & \\
\hline $50 \mathrm{SI}$ & 1.000 & 0.003 & 0.326 & 1.000 & & & & & & & \\
\hline 250 B 0 & 0.260 & 0.498 & 0.002 & 0.378 & 1.000 & & & & & & \\
\hline $250 \mathrm{~B} \mathrm{I}$ & 0.042 & 0.958 & 0.000 & 0.070 & 0.998 & 1.000 & & & & & \\
\hline $50 \mathrm{~B} 0$ & 0.913 & 0.061 & 1.000 & 0.971 & 0.983 & 0.602 & 1.000 & & & & \\
\hline $50 \mathrm{~B} 1$ & 0.000 & 0.102 & 0.000 & 0.000 & 0.001 & 0.005 & 0.000 & 1.000 & & & \\
\hline $250 \mathrm{M} 0$ & 0.000 & 0.000 & 0.033 & 0.000 & 0.000 & 0.000 & 0.000 & 0.000 & 1.000 & & \\
\hline $250 \mathrm{Ml}$ & 1.000 & 0.000 & 0.888 & 0.996 & 0.061 & $0.00 \mathrm{l}$ & 0.501 & 0.000 & 0.001 & 1.000 & \\
\hline $50 \mathrm{M} 0$ & 0.000 & 0.000 & 0.073 & 0.000 & 0.000 & 0.000 & 0.000 & 0.000 & 1.000 & 0.002 & 1.000 \\
\hline $50 \mathrm{Ml}$ & 0.978 & 0.032 & 0.048 & 0.996 & 0.925 & 0.421 & 1.000 & 0.000 & 0.000 & 0.684 & $0.000 \quad 1.000$ \\
\hline
\end{tabular}

Table 4.2: Levels of significance for interactions between concentration (low, $50 \mathrm{mg} \mathrm{l}^{-1}$, high, $250 \mathrm{mg} \mathrm{I}^{-1}$ ), composition (bentonite, B, Sillikers clay, S, drill-mud, $M$ ) and turbulence (grid off, 0 , grid on, 1 ), on the variable settling velocity, $\left(W_{50}\right)$, using Tukey post hoc analysis. 
Images obtained at the same time as the suspended sediment samples were collected, showed that floc diameter increased after the flocculator was stopped in the bentonite and Sillikers clay treatments and in the turbulent drill mud runs. Increase in floc size before settling has been observed by van Leussen (1986) for kaolinite in a grid stirred column flocculator and by Milligan (1995) for estuarine sediments in a 5m carousel flume. The result of floc development during the initial stages of the settling can be seen in the plots of cumulative volume determined from the volume concentrations of samples withdrawn (Fig. 4.1). Similar to the results of Kranck (1980) and Milligan (1995), the plots for the high turbulence cases show little or no settling during the early sample periods as flocs form, followed by a rapid drop in volume concentration as the flocs settle. In the case of the low concentration bentonite treatments, no settling was found before 22 minutes as opposed to the high concentration samples which showed rapid floc settling after the 11 minute sample (fig. 4.1a). This increase in settling velocity with increasing concentration as a result of more rapid flocculation of the suspension was reported by Kranck (1980) for still water settling with Sillikers clay in salt water. The same effect from concentration was found in the drill mud samples but surprisingly, not for Sillikers clay. Why the settling behaviour of the partially flocculated suspensions of Sillikers clay did not conform to behaviour of previous studies (Kranck, 1980, 1986) starting from a fully disaggregated suspension would be worth investigating in another study. At the end of the floc settling period some material remained in suspension (fig. 4.1). The greatest amount of which occurred in the low concentration turbulent Sillikers clay and bentonite 


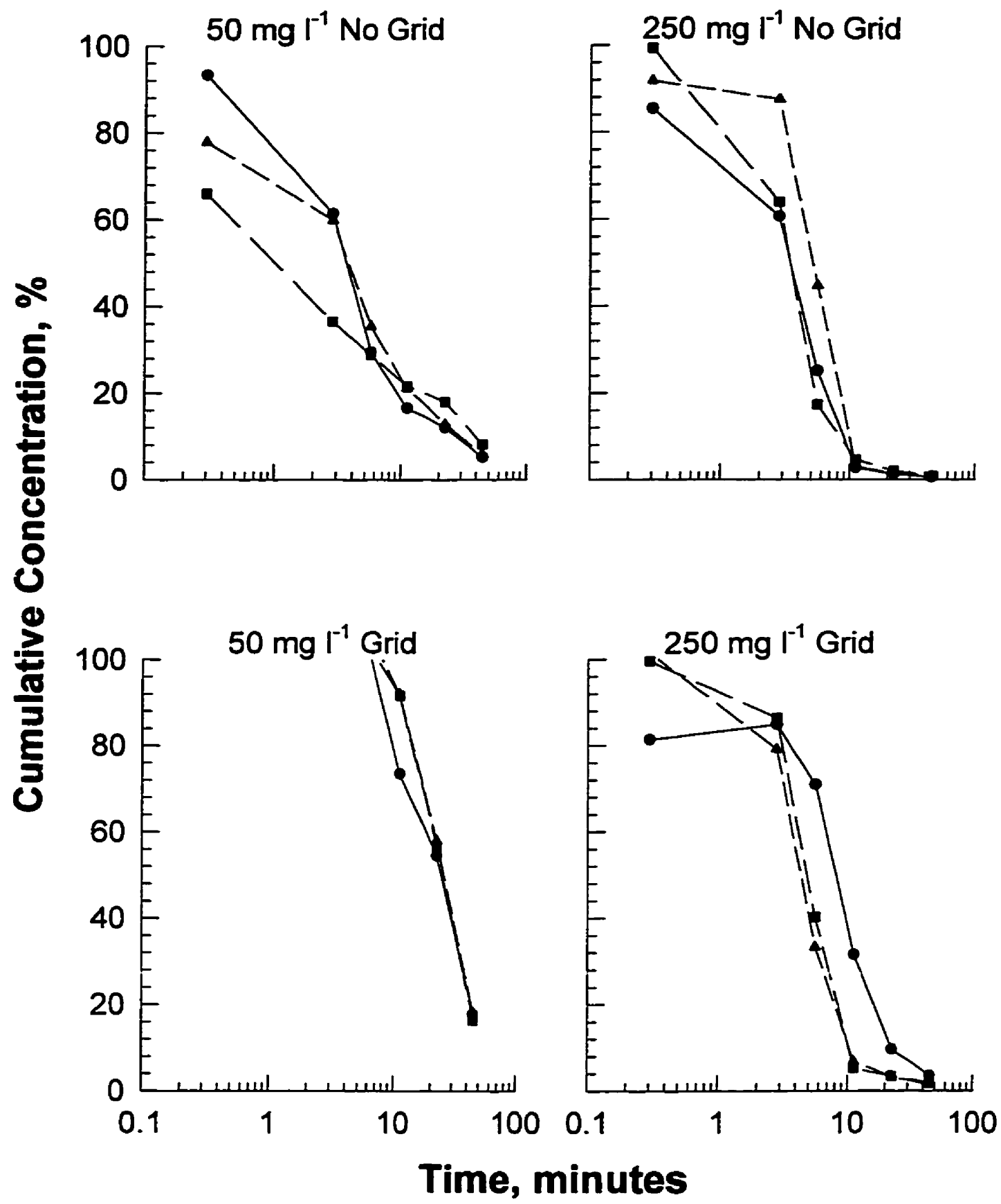

Figure 4.la: Plots of percent total cumulative concentration vs time for samples withdrawn at $0.15 \mathrm{~m}$ depth during still water settling. Symbols and lines represent replicates. 


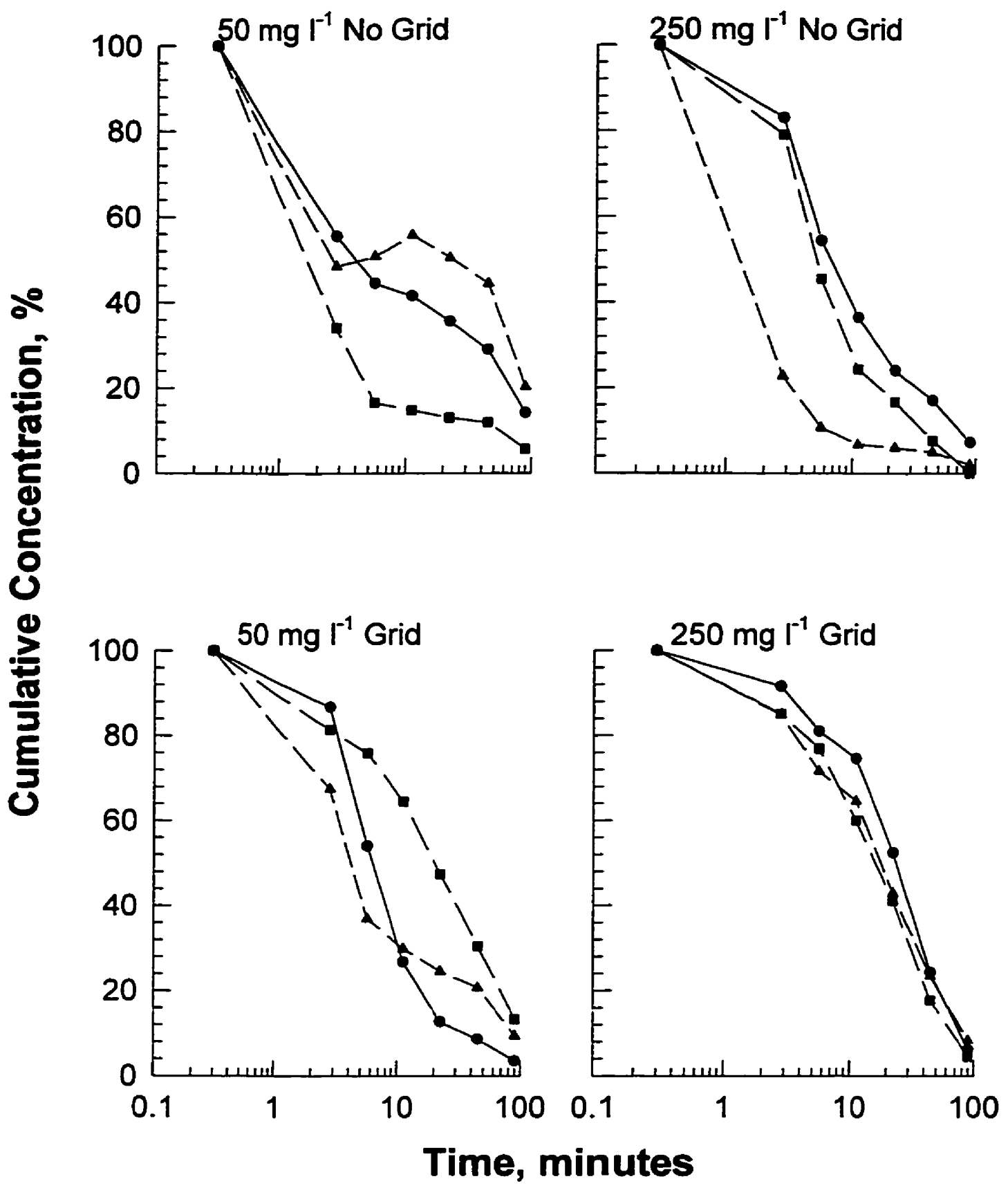

Figure 4.lb: Plots of percent total cumulative concentration vs time for samples withdrawn at $0.15 \mathrm{~m}$ depth during still water settling. Symbols and lines represent replicates. 


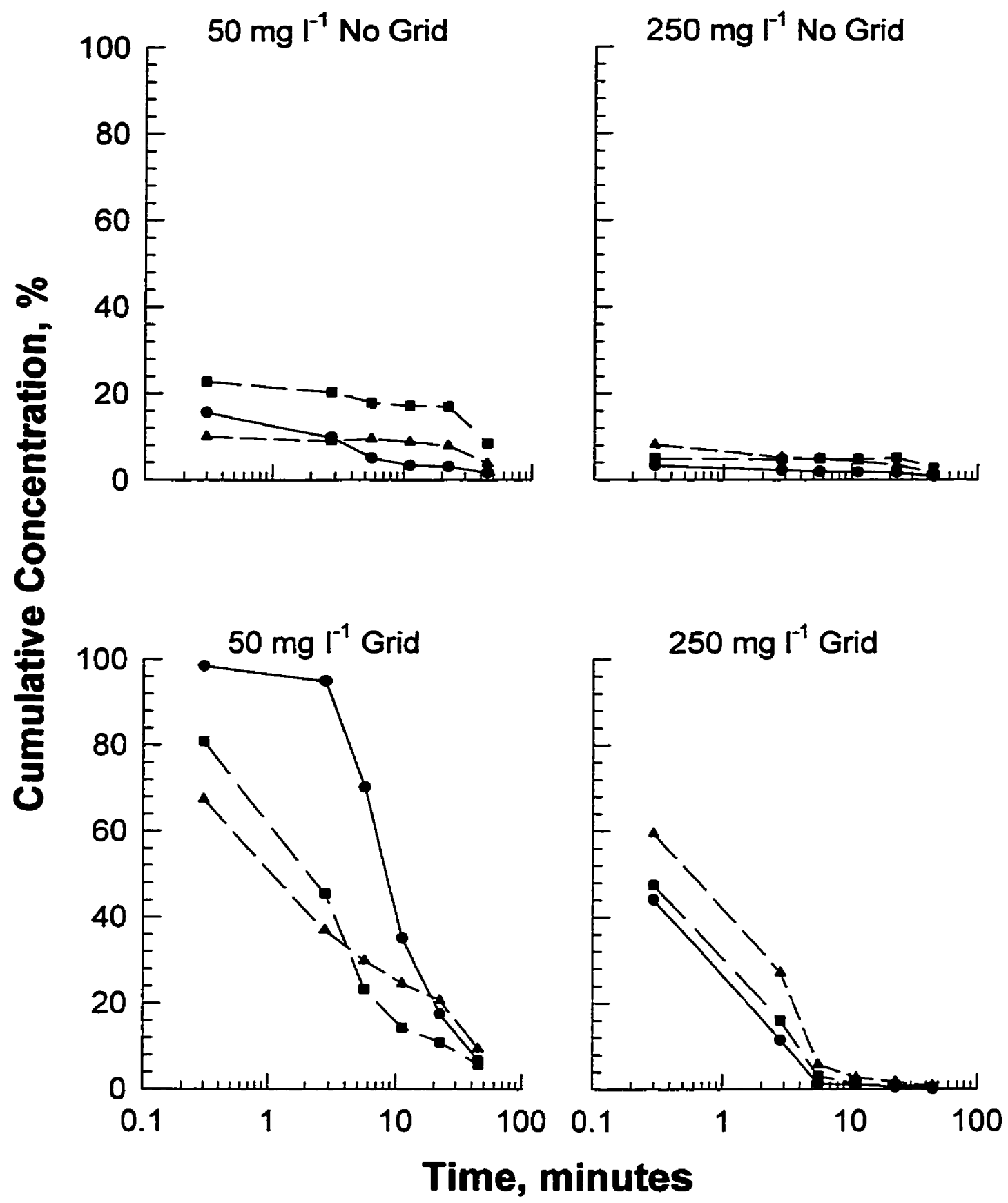

Figure 4.Ic: Plots of percent total cumulative concentration vs time for samples withdrawn at $0.15 \mathrm{~m}$ depth during still water settling. Symbols and lines represent replicates. 
samples and represented material which was not incorporated into the more rapid settling flocs. In contrast, plots for the low turbulence drill mud runs show that $75-95 \%$ of the initial concentration settles within the first sampling period. The amount of material stranded appears to be inversely related to concentration and directly related to turbulence level. Conceivably, this is a result of the non-isotropic nature of the turbulence within the flocculator.

Although bentonite formed the largest flocs in low turbulence, $\approx 1000 \mu \mathrm{m}$, the $\mathrm{w}_{50}$ for the drill mud samples was an order of magnitude greater under the same conditions. The nonturbulent drill mud samples had $\mathrm{w}_{50}$ values ranging from 0.4 to $0.5 \mathrm{~cm} \mathrm{~s}^{-1}$, whereas those for bentonite ranged from 0.02 to $0.05 \mathrm{~cm} \mathrm{~s}^{-1}$ (table 2.1 , fig. 4.2). The $\mathrm{w}_{50}$ values derived for the non-turbulent drill mud samples were conservative estimates since over $90 \%$ of the material in suspension had settled below $0.15 \mathrm{~m}$ within the first sample period. In cases where the cumulative curve was not defined and the graphical method of Owen (1976) could not be applied, $w_{50}$ was defined using the mid-point between the total concentration and the concentration of the first sample. Settling velocities of $1-2 \mathrm{~cm} \mathrm{~s}^{-1}$ have been recorded for drill mud flocs of similar diameter formed under the same conditions in a $0.20 \mathrm{~m}$ wide annular flume (Muschenheim et al., in prep). Sillikers clay had non-turbulent settling velocities greater than those for bentonite in the low concentration samples $\left(0.11-0.15 \mathrm{~cm} \mathrm{~s}^{-1}\right)$ but similar velocities in two of the three replicates at high concentration. Settling velocities for the turbulent cases showed the 


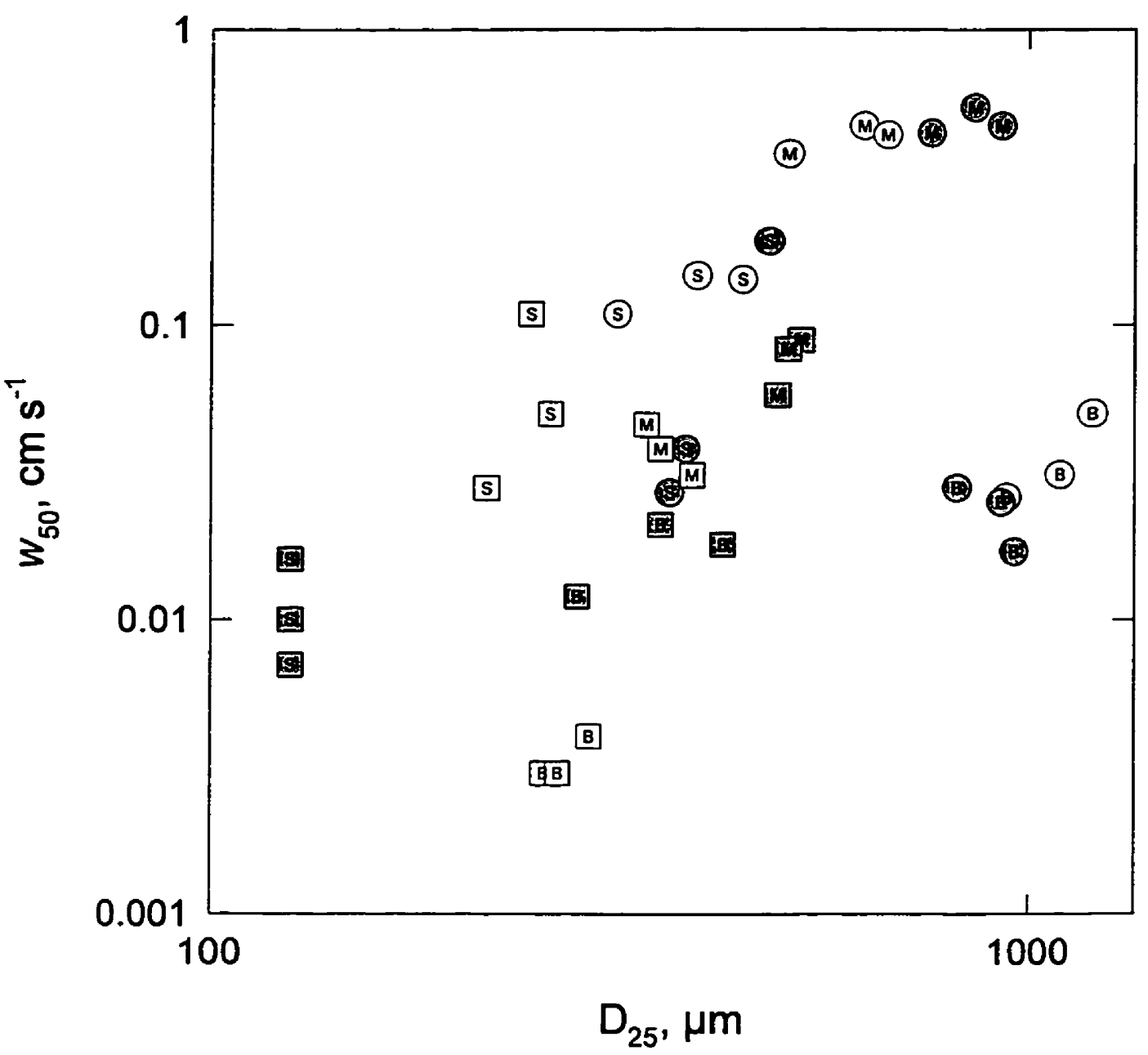

Figure 4.2. Settling velocity, ( $\left.w_{50}\right)$, vs maximal floc size, $\left(D_{25}\right)$, for bentonite $(B)$, Sillikers clay $(S)$, and drill mud (M) flocs formed under high (squares) and low (circles) turbulence at high (grey) and low (white) concnetration. 
same trend, with bentonite velocities being less than those for drill mud in all cases and less than the values for Sillikers clay at low concentration but not high.

Differences in the settling behaviour of the three materials resulted in three distinct compositional groupings, with a region of overlap in the central portion of the graph, in the plot of settling velocity and maximal floc size (fig. 4.2). The bentonite samples form a group of points below those of both Sillikers clay and drill mud indicating the formation of lower density flocs. The groupings agree with observations of clay settling which show that illitic material settles more rapidly than kaolinitic materials which settle much more rapidly than suspensions of montmorillonite (Bennett and Hulbert, 1986). The Sillikers clay samples appear to form a continuous distribution of floc size and settling velocity with drill mud suggesting that Sillikers clay forms flocs with similar densities and fractal dimension (Logan and Kilps 1995). 


\section{CHAPTER 5:}

\subsection{Discussion:}

Results from the examination of both maximal floc size and settling velocity indicate that turbulence and composition dominate the behaviour of flocculated suspensions and that concentration plays a part only in the initial development of aggregates or when turbulence decreases. Although only two concentrations were investigated, the range of values expected in most coastal waters fall below the maximum investigated. The results do not eliminate the possibility of concentration limiting floc size at much higher concentrations but they do suggest that including a floc break-up term due to concentration in models of particle aggregation on the continental shelf is not necessary.

The effect of turbulence on maximal floc size demonstrated in this experiment using seawater and materials discharged during offshore hydrocarbon development agrees with the results of previous experiments. The negative effect of increasing turbulence on maximal floc size is clearly demonstrated in the experiments but the experience of designing the grid emphasizes the difficulty of scaling turbulence in the laboratory. Calculating the power input for the three grids gives shear rates of the same order as those found in offshore regions but the scale at which the energy is introduced has a very large effect on maximal floc size. Caution is warranted when attempting to transfer laboratory floc sizes and conformations to natural systems. 
The most important finding of this work from the standpoint of modelling floc behaviour in natural systems is the confounding effect from composition on both the maximal floc size and the settling behaviour of the three materials examined. In the simplest case, bentonite flocs were larger but settled slower than those formed from Sillikers clay in accordance with the ranking of kaolinite, illite and montmorillonite described by Bennett and Hurlbert (1986). The behaviour of bentonite in suspension is dominated by physicochemical processes whereas in Sillikers clay, mechanical processes dominate the kaolinite portion and a combination of both processes control the behaviour of the illite fraction (Bennett and Hurlbert, 1986). The ability of bentonite to adsorb organic material into its lattice structure makes it more susceptible to flocculation resulting in large low density flocs with low settling velocities whereas the Sillikers clay suspensions are more susceptible to disaggregation as a result of grid passage due to weaker bond strengths between the kaolinite and illite. In the simplest terms, the drill mud sample can be considered a mixture of Sillikers clay (ground rock) and bentonite (drilling fluid) as can be seen in the particle size spectra for the three materials (fig. 2.8). The presence of bentonite and other substances in the drill mud sample results in the formation of large, robust, aggregates with high settling velocities. The fact that relatively large drill mud flocs were found under turbulent conditions suggests that the presence of expanding three layer clay and/or the other components in the drilling fluid increases the bond strength in the drill mud flocs. Varying the relative proportions of the components in a drill mud discharge would likely alter the maximal floc size and settling velocity of the suspension 
and the sample used in this experiment is only one of a wide range of possible formunlations. Barite or other weighting agents, for example, could change the behaviour of the mud in suspension.

Further complications for the development of flocculation models result from varying concentrations of naturally occurring organic material found in relation to phytoplankton production in the coastal zone. Field studies carried out on the Scotian Shelf have revealed both widespread occurrences of natural floc in suspension (unpubl) and localised occurrences of high floc concentration in association with offshore drilling activity (Muschenheim et al., 1995a,b). Although much of the material in suspension is phytoplankton and other detritus, drill mud has been found in association with flocs in the benthic boundary layer (BBL) (Muschenheim et al., 1995a). The occurrence of high concentrations of phytoplankton and the increased levels of colloidal organic carbon associated with them (Kepkay et al., 1993, Niven et al., 1995) can be expected to increase the flocculation rate of fine particulates discharged and hence increase the flux of material to the BBL. With settling velocities on the order of those found in this experiment, drill mud flocs can be expected to reach the BBL during slack water periods on the Scotian Shelf. Increased turbulence and concentration within the BBL will, based on the results of this study, change the size and settling properties of the resuspended flocs. Although concentration has no apparent effect on maximal floc size, the concentration in the 
discharge plume could affect the dispersal of a discharge plume by altering the aggregation rate.

The method used in this experiment to describe the settling of the suspension is widely used in studies of sediment behaviour in estuaries (Puls, 1988). However, settling velocities determined using in situ methods such as that of Fennessey et al. (1994) and Ten Brinke (1994) have found much higher values than those from Owen tube analysis in estuarine waters. Amos and Mosher (1985) found that settling velocities calculated from concentration profiles exceeded Owen tube values by almost an order of magnitude for samples collected in the Bay of Fundy. It is apparent from the results of the still water settling portion of this experiment that the initial size and type of material in suspension has a marked effect on the settling velocity. Varying amounts of flocculation occurred before the onset of settling with the greatest difference between samples occurring with respect to turbulence and composition. In the case of Owen tube analysis, the settling velocity determined will be affected by the degree to which the suspension is disaggregated during sampling not only as a result of turbulence in the tube but also as a result of the composition of the flocs in suspension. Correction factors accounting for aggregation after closing the tube such as suggested by Puls (1988) will also be affected by the composition of the suspension. 


\subsection{Conclusion:}

The goals of this study were to examine the dependence of maximal floc size and settling velocity of a suspension on the three factors most often proposed for controlling the development of large aggregates in suspension. As a result of field observations and the demands to evaluate the fate of particulate material from offshore development, this study concentrated on the behaviour of a material presently being discharged by drilling rigs in the coastal zone and attempted to expose it and its component parts to turbulence levels of the order expected in a reasonably energetic offshore environment. Aggregates formed under laboratory conditions can not be considered to be the same as those formed in nature because producing isotropic, low energy turbulence typical of field sites is difficult, if not impossible, in the laboratory. However, by using a comparative study and low dissipation energy in the flocculator, it was possible to evaluate the relative importance of three of the controlling terms used in aggregation models. Most models such as that of Jackson (1995) and Hill (1996) contain three major terms to describe the development of a flocculated suspension: 1) particle number or concentration, 2) particle adhesion efficiency or stickiness and 3) particle break-up, most often due to an applied shear. Concentration as a break up mechanism resulting from particle collisions has also been suggested by Lick and Lick (1988). In the series of experiments described above, analysis of the maximal floc size after 20 hours in an inverting column allowed the relative importance of the factors examined to be evaluated. Findings in this study show 
that although turbulence appears to dominate maximal floc size, it can not be considered in isolation when predicting floc size. Maximal floc size was smaller at high turbulence but highly significant compositional effects were also found in the comparisons of size between materials in suspension and in the settling behaviour of the flocs formed. Flocs formed from used drilling mud under turbulent conditions were larger than those of the other two materials and of the same size or greater in low turbulence. More importantly for particle transport though, their settling velocities were up to an order of magnitude greater than those of either bentonite or Sillikers clay. Concentration was not found to have a significant effect on maximal floc size for concentrations within the range of those found in most coastal waters. Equilibrium floc size did not change with increased concentration but the rate at which a new floc population was established when turbulence ceased appeared in most case to adhere to aggregation theory which suggests a strong dependence on particle number. Increased concentration resulted in more rapid floc formation and settling in still water in the turbulent samples as predicted by aggregation models.

The results of this study suggest that predicting the behaviour of particulate material disposed of in the open ocean will require not only a knowledge of the turbulent conditions, but also of its composition. A thorough examination of the structure and settling behaviour of flocs of varying composition formed under natural conditions is the obvious next step from this study. 
Appendix 1

\begin{tabular}{|c|c|c|c|c|c|c|c|c|c|c|c|c|}
\hline \multirow[b]{2}{*}{ Diameter } & \multicolumn{3}{|c|}{50 B 0} & \multicolumn{3}{|c|}{50 B 1} & \multicolumn{3}{|c|}{250 B 0} & \multicolumn{3}{|c|}{250 B I } \\
\hline & $\mathbf{I}$ & 2 & 3 & 1 & 2 & 3 & $\mathbf{I}$ & 2 & 3 & 1 & 2 & 3 \\
\hline 128 & 0.49 & 0.30 & 0.28 & 14.94 & 10.91 & 17.59 & 0.07 & 0.14 & 0.05 & 13.05 & 4.29 & 4.59 \\
\hline 161 & 1.10 & 0.63 & 0.57 & 24.46 & 18.16 & 23.23 & 0.13 & 0.30 & 0.17 & 22.02 & 8.74 & 10.10 \\
\hline 203 & 1.32 & 0.83 & 0.75 & 20.32 & 20.23 & 16.73 & 0.22 & 0.45 & 0.23 & 18.47 & 10.32 & 12.62 \\
\hline 256 & 2.49 & 1.46 & 1.39 & 19.72 & 20.97 & 18.05 & 0.67 & 0.99 & 0.55 & 18.97 & 16.68 & 22.2 \\
\hline 323 & 4.33 & 2.55 & 3.03 & 6.31 & 16.58 & 7.43 & 1.67 & 2.74 & 1.45 & 13.10 & 18.19 & 25.9 \\
\hline 406 & 8.48 & 9.17 & 6.18 & 9.47 & 5.85 & 6.37 & 4.11 & 5.62 & 3.54 & 8.67 & 20.87 & 20.2 \\
\hline 512 & 18.25 & 11.67 & 9.29 & & 3.90 & 4.25 & 11.94 & 11.51 & 7.74 & 1.08 & 8.22 & 2.75 \\
\hline 645 & 16.96 & 15.00 & 12.74 & & & & 13.99 & 15.71 & 10.08 & 0.72 & 3.80 & \\
\hline 813 & 16.96 & 20.00 & 21.49 & & & & 25.11 & 25.35 & 18.33 & & 2.53 & \\
\hline 1024 & 17.69 & 11.67 & 20.87 & & & & 22.46 & 24.28 & 26.07 & & 5.06 & \\
\hline 1290 & 11.80 & 20.00 & 15.96 & & & & 13.07 & 7.14 & 17.11 & & & \\
\hline 1625 & & 6.67 & 7.37 & & & & 3.27 & 5.71 & 11.41 & & & \\
\hline \multirow[t]{2}{*}{2048} & & & & & & & 3.27 & & 3.26 & & & \\
\hline & \multicolumn{3}{|c|}{$50 \mathrm{SO}$} & \multicolumn{3}{|c|}{$50 \mathrm{~S} 1$} & \multicolumn{3}{|c|}{250 S 0} & \multicolumn{3}{|c|}{$250 \mathrm{~S} 1$} \\
\hline iameter & $\mathbf{I}$ & 2 & 3 & 1 & 2 & 3 & 1 & 2 & 3 & 1 & 2 & 3 \\
\hline 128 & 2.66 & 2.09 & 4.80 & 12.95 & 13.61 & 16.11 & 4.38 & 4.24 & 1.03 & & & \\
\hline 161 & 6.81 & 7.41 & 8.19 & 21.54 & 29.53 & 22.96 & 11.49 & 12.01 & 3.55 & & & \\
\hline 203 & 14.86 & 9.85 & 8.13 & 13.94 & 19.01 & 20.82 & 11.84 & 16.06 & 5.70 & & No Data & \\
\hline 256 & 39.13 & 19.24 & 15.87 & 6.84 & 16.24 & 17.68 & 20.29 & 20.43 & 11.76 & & & \\
\hline 323 & 21.80 & 27.17 & 22.17 & 4.05 & 7.38 & 6.84 & 23.22 & 15.27 & 18.81 & & & \\
\hline 406 & 5.94 & 22.64 & 15.12 & 5.07 & 5.91 & 4.56 & 17.83 & 19.76 & 26.80 & & & \\
\hline 512 & 7.93 & 10.87 & 14.11 & 10.14 & 2.95 & 4.56 & 9.38 & 10.78 & 21.30 & & & \\
\hline 645 & & & 6.05 & 12.16 & & & & & 9.23 & & & \\
\hline 813 & & & 4.03 & 8.11 & & & & & 1.42 & & & \\
\hline
\end{tabular}

\begin{tabular}{cccccccccccccc} 
& & $\mathbf{5 0} \mathbf{M ~ 0}$ & \multicolumn{4}{c}{$\mathbf{5 0} \mathbf{M} \mathbf{1}$} & \multicolumn{3}{c}{$\mathbf{2 5 0} \mathbf{M} \mathbf{0}$} & \multicolumn{3}{c}{$\mathbf{2 5 0} \mathbf{M} \mathbf{1}$} \\
Diameter & $\mathbf{1}$ & $\mathbf{2}$ & $\mathbf{3}$ & $\mathbf{1}$ & $\mathbf{2}$ & $\mathbf{3}$ & $\mathbf{1}$ & $\mathbf{2}$ & $\mathbf{3}$ & $\mathbf{1}$ & $\mathbf{2}$ & $\mathbf{3}$ \\
128 & 0.20 & 0.15 & 0.17 & 3.04 & 4.42 & 4.55 & 0.07 & 0.02 & 0.27 & 0.92 & 0.89 & 1.23 \\
161 & 0.83 & 0.65 & 0.92 & 7.91 & 11.42 & 13.01 & 0.17 & 0.07 & 0.66 & 2.76 & 2.37 & 3.17 \\
203 & 1.60 & 1.24 & 2.02 & 10.67 & 13.40 & 15.50 & 0.50 & 0.14 & 1.18 & 3.80 & 4.34 & 5.00 \\
256 & 4.14 & 5.56 & 5.24 & 19.61 & 21.73 & 20.72 & 1.25 & 0.41 & 3.37 & 8.21 & 8.23 & 11.33 \\
323 & 11.17 & 17.56 & 10.79 & 24.20 & 24.08 & 22.70 & 3.47 & 1.81 & 7.04 & 17.86 & 17.75 & 21.18 \\
406 & 24.51 & 32.43 & 20.84 & 22.53 & 13.51 & 14.63 & 10.70 & 6.62 & 14.27 & 21.97 & 25.65 & 26.69 \\
512 & 25.67 & 29.48 & 24.41 & 10.01 & 7.64 & 4.88 & 21.02 & 17.59 & 23.15 & 26.51 & 24.84 & 19.86 \\
645 & 21.56 & 10.72 & 13.81 & 1.11 & 2.35 & & 16.61 & 22.82 & 20.00 & 11.62 & 12.42 & 8.69 \\
813 & 8.21 & 2.14 & 7.89 & & & 2.44 & 22.32 & 24.04 & 24.73 & 4.04 & 3.24 & \\
1024 & 2.05 & & 5.92 & & & & 13.49 & 18.12 & 5.26 & 2.02 & & 2.48 \\
1290 & & & 7.89 & & & & 6.23 & 8.36 & & & & \\
1625 & & & & & & & 4.15 & & & & &
\end{tabular}

Data from analysis of images for 3 replicates varying concentration (low, $50 \mathrm{mg} \mathrm{I}^{-1}$, high, $250 \mathrm{mg} \mathrm{l}^{-1}$ ), composition (bentonite, B, Sillikers clay, S, drill-mud, M) and turbulence (grid off, 0 , grid on, 1 ). 
Appendix 2

\begin{tabular}{|c|c|c|c|c|c|c|c|c|c|c|c|c|}
\hline \multirow[b]{2}{*}{ Time } & \multicolumn{3}{|c|}{250 B 0} & \multicolumn{3}{|c|}{250 B 1} & \multicolumn{3}{|c|}{50 B 0} & \multicolumn{3}{|c|}{50 B 1} \\
\hline & 1 & 2 & 3 & 1 & 2 & 3 & 1 & 2 & 3 & 1 & 2 & 3 \\
\hline 0.30 & 85.43 & 99.31 & 91.78 & 81.39 & 99.54 & 100.41 & 93.30 & 66.00 & 77.82 & 113.47 & 105.26 & 103.32 \\
\hline 2.81 & 60.64 & 64.01 & 87.56 & 84.85 & 86.34 & 79.13 & 61.38 & 36.52 & 59.87 & 128.32 & 109.89 & 105.37 \\
\hline 5.63 & 5.05 & 17.21 & 44.71 & 70.89 & 40.18 & 33.25 & 29.43 & 28.81 & 35.41 & 104.29 & 103.58 & 105.87 \\
\hline 11.25 & 2.71 & 4.50 & 2.89 & 31.49 & 5.22 & 6.80 & 16.53 & 21.66 & 21.15 & 73.51 & 91.62 & 91.98 \\
\hline 22.50 & 1.21 & 1.92 & 1.46 & 9.57 & 3.41 & 3.26 & 12.08 & 17.98 & 12.80 & 54.48 & 56.55 & 58.01 \\
\hline \multirow[t]{3}{*}{45.00} & 0.47 & 0.72 & 0.67 & 3.46 & 1.78 & 1.40 & 5.21 & 8.13 & 5.70 & 17.73 & 16.26 & 18.21 \\
\hline & \multicolumn{3}{|c|}{$250 \leq 0$} & \multicolumn{3}{|c|}{$250 \mathrm{~S} 1$} & \multicolumn{3}{|c|}{$50 \mathrm{SO}$} & \multicolumn{3}{|c|}{$50 \mathrm{~S} 1$} \\
\hline & 1 & 2 & 3 & 1 & 2 & 3 & 1 & 2 & 3 & 1 & 2 & 3 \\
\hline 0.30 & 83.15 & 79.19 & 22.80 & 91.61 & 85.11 & 84.86 & 55.52 & 34.04 & 48.36 & 86.69 & 81.35 & 67.41 \\
\hline 2.81 & 54.50 & 45.59 & 10.75 & 81.02 & 76.91 & 71.66 & 44.47 & 16 & 50.81 & 53.99 & 9 & 36.92 \\
\hline 5.63 & 36.51 & 24.43 & 6.74 & 74.63 & 60.00 & 64.56 & 41.50 & 14 & 55.72 & 26.71 & 64.46 & 29.81 \\
\hline 11.2 & 24.07 & 16.78 & 5.99 & 52.40 & 41.08 & 42.92 & 35.58 & 13.03 & 50.44 & 12.66 & 47.36 & 24.53 \\
\hline 22.50 & 17.13 & 7.69 & 4.96 & 24.25 & 17.64 & 23.40 & 28.91 & 11.93 & 44.39 & 8.56 & 30.46 & 20.66 \\
\hline \multirow[t]{3}{*}{45.00} & 7.20 & & 1.97 & 6.09 & 4.43 & 8.28 & 14.13 & 5.66 & 20.27 & 3.51 & 13.24 & 9.38 \\
\hline & \multicolumn{3}{|c|}{$250 \mathrm{M} \mathrm{O}$} & \multicolumn{3}{|c|}{$250 \mathrm{M} 1$} & \multicolumn{3}{|c|}{50 M 0} & \multicolumn{3}{|c|}{50 M 1} \\
\hline & 1 & 2 & 3 & 1 & 2 & 3 & 1 & 2 & 3 & $\mathbf{I}$ & 2 & 3 \\
\hline 0.30 & 3.29 & 5.03 & 8.10 & 44.04 & 47.45 & 59.43 & 15.64 & 22.76 & 10.03 & 98.42 & 80.90 & 67.41 \\
\hline 2.81 & 2.26 & 4.68 & 5.14 & 11.42 & 15.91 & 27.08 & 9.83 & 20.32 & 8.94 & 94.91 & 45.50 & 36.92 \\
\hline 5.63 & 1.91 & 4.86 & 4.91 & 1.31 & 3.01 & 5.69 & 5.05 & 17.84 & 9.44 & 70.16 & 23.24 & 29.81 \\
\hline 11.25 & 1.75 & 4.71 & 4.25 & 0.94 & 1.17 & 2.66 & 3.33 & 17.11 & 8.76 & 35.08 & 14.27 & 24.53 \\
\hline 22.50 & 1.63 & 5.07 & 3.36 & 0.44 & 0.92 & 1.67 & 3.00 & 16.93 & 7.81 & 17.48 & 10.87 & 20.66 \\
\hline 45.00 & 0.76 & 2.63 & 1.58 & & 0.42 & 0.65 & 1.62 & 8.45 & 3.78 & 6.66 & 5.70 & 9.38 \\
\hline
\end{tabular}

Values for total cumulative \% settled, determined from volume concentrations for 3 replicate treatments varying concentration (low, $50 \mathrm{mg} \mathrm{l}^{-1}$, high, $250 \mathrm{mg} \mathrm{I}^{-1}$ ), composition (bentonite, B, Sillikers clay, S, drillmud, $M$ ) and turbulence (grid off, 0 , grid on, 1 ). 
LIST OF SYMBOLS:

$\varepsilon$

$\rho$

$v$

g

G

h

m

$\mathrm{t}$

v turbulent energy dissipation rate

density

kinematic viscosity

acceleration due to gravity

shear rate

height of column

mass

time

volume of column 
Alldredge, A.L. and C.C. Gotschalk, 1989. Direct observations of the mass flocculation of diatom blooms: characteristics, settling velocities and formation of diatom aggregates. Deep Sea Res., 36, 2, 159-171.

Allersma, E., 1980. Mud in estuaries and along coasts. Proc. Int. Symp. River Sed., Beijing, 663-685 and 1285-1289.

Amos, C.L. and D.C. Mosher, 1985. Erosion and deposition of fine grained sediments from the Bay of Fundy. Sedimentology, 32, 815-832.

Bennett, R.H. and M.H. Hurlbert, 1986. Clay Microstructure, International Human Resources Dev. Corp., Boston, 16lpp.

Berhane, I., R.W. Sternberg, G.C. Kineke, T.G. Milligan and K. Kranck, in press. The variability of suspended aggregates on the Amazon Continental Shelf, Cont. Shelf. Res.

Brumley, B.H., and G.H. Jirka, 1987. Near-surface turbulence in a grid-stirred tank, J. Fluid Mech., 183, 235-263.

Brunk, B., M. Weber-Shirk, A. Jensen, G. Jirka, and L.W. Lion, 1996. Modelling natural hydrodynamic systems with a differential-turbulence column. J. Hydraulic Eng., $122,7,373-380$.

Burban, P.-Y, W. Lick and J. Lick, 1989. The flocculation of fine-grained sediments in estuarine waters, J. Geophys. Res., 94, 6, 8323-8330.

Cranford, P.J. and D.C. Gordon, 1991. Chronic sublethal impact of mineral oil-based drilling mud cuttings on adult sea scallops, Mar. Poll. Bul., 22, 7, 339-344.

Cranford, P.J. and D.C. Gordon, 1992. The influence of dilute clay suspensions on sea scallop (Placopecten Magellanicus) feeding activity and tissue growth, Neth. J. Sea Res., 30, 107-120.

Dabros, M.J. and Mudie, P.J., 1986. An automated microscope system for image analysis in palynology and micropaleontology, in Current Research, Part A, Geological survey of Canada, Paper 86-1A, p. 107-112.

Day, R.W. and G.P. Quinn, 1989. Comparison of treatments after analysis of variance in ecology, Ecological Monographs, 59, 4, 433-463. 
Dickey, T.D. and G.L. Mellor, 1980. Decaying turbulence in neutral and stratified fluids, J. Fluid Mech., 99, 13-31.

Edgerton, H.E., 1979. Silhouette photography of small active subjects, J. Microscopy, $110,1,79-81$.

Edgerton, H., P. Ortner, W. McElroy, G. Hayward and D. Jones, 1981. An in-situ plankton camera, in Oceans ' 81 , conference proceedings, IEEE, p 558-559.

Eisma, D., 1986. Flocculation and de-flocculation of suspended matter in estuaries, Neth. J. Sea Res., 183-199.

Eisma, D., J.P. Boon, R. Groenewegen, V. Ittekkot, J. Kalf and W.G. Mook, 1983. Observations on macro-aggregates, particle size and organic composition of suspended sediment in the Ems estuary, Mitt. Geol. Palaeont. Inst. Univ. Hamburg. SCOPE/UNEP Sonderb. 55, 295-314.

Eisma, D., T. Schuhmacher, H. Boekel, J. Heerwaarden, H. Van Franken, M. Laan, A. Vaars, F. Eugenraam and J. Kalf, 1990. A camera and image analysis system for in situ observations of flocs in natural waters. Neth. J. Sea Res., 27, 43-56.

Eisma, D., P. Bernard, G.C. Cadee, V. Ittekot, J. Kalf, R. Laane, J.M. Martin, W.G. MooK, A. van Put, and T. Schuhmacher, 1992. Suspended-matter particle size in some West-European estuaries; Part ii: A review on floc formation and break-up, Neth. J. Sea Res., 28, 3, 215-220.

Eisma, D. and A. Li, 1993, Changes in suspended-matter floc size during the tidal cycle in the Dollard Estuary, Neth. J. Sea Res., 31(2), 107-117.

Fennessey, M.J., K.R. Dyer and D.A. Huntley, 1994. INSSEV: An instrument to measure the size and settling velocity of flocs in situ, Mar. Geol. 117: 107-117.

Folk, R.L., 1980. Petrology of Sedimentary Rocks, Hemphill Publishing Co., Austin, Tx.

Gibbs, R.J., 1981. Floc breakage by pumps, J. Sed. Petrology, 51, 670-672.

Gibbs, R.J., 1982. Floc stability during Coulter Counter analysis, J. Sed. Petrol., 52, 657670.

Gibbs, R.J. and L.N. Konwar, 1982. Effect of pipetting on mineral flocs, Environ. Sci. Technol., 16, 119-121. 
Hannah, C.G., Y.Shen, J.W. Loder and D.K. Muschenheim, 1995. bblt: Formulation and exploratory applications of a benthic boundary layer transport model, Can. Tech. Rep. Hydrogr. Ocean Sci., 166, vi + 52pp.

Heffler, D., J.P.M. Syvitski and K.W. Asprey, 1991. The floc camera. In: J.P.M. Syvitski. Theory, methods and applications of particle size analysis. Cambridge Univ. Press, N.Y.: 209-221.

Hill, P.S., A.R.M. Nowell and P.A. Jumars, 1992. Encounter rate by turbulent shear of particles similar in diameter to the Kolmogorov scale, J. Mar. Res., 50, 643-668.

Hill, P.S., 1996. Comparison of two models of aggregation in continental shelf bottom boundary layers, Deep Sea Res. I, 43, 5, 679-702.

Jackson, G.A., 1995. Comparing observed changes in particle size spectra with those predicted using coagulation theory, Deep Sea Res. II, 42, 1, 159-184.

Jellett, J.F., W.K.W. Li, P.M. Dickie, A. Boraie and P.E. Kepkay, 1996. Metabolic activity of bacterioplankton communities assessed by flow cytometry and single carbon substrate utilization. Mar.Ecol. Prog. Ser. 136: 213-225.

Johnson, B.D., K. Kranck and D.K. Muschenheim, 1990. Physico-chemical factors in particle aggregation, in: The Biology of Particles in Aquatic Environments, R. Wotton, ed., CRC Press, Florida, 57-81.

Kepkay, P.E., S.E.H. Niven and T.G. Milligan, 1993. Low molecular weight and colloidal DOC production during a phytoplankton bloom. Mar. Ecol. Prog. Ser., $100,233-244$.

Kranck, K., 1980. Experiments on the significance of flocculation in the settling behaviour of fine grained sediment in still water, Can. J. Earth Sci., 17, 15171526.

Kranck, K., 1986. Settling behaviour of cohesive sediment, in: J. Mehta, ed., Estuarine Cohesive Sediment Dynamics, Springer-Verlag, 151-169.

Kranck, K., 1990. Interparticle grain size relationships resulting from flocculation, in: R.H. Bennett, W.R. Bryant and M.H. Hulbert, eds., Microstructure of FineGrained Sediments: From Mud to Shale. Frontiers in Sed. Geol., Springer-Verlag, N.Y., 125-130.

Kranck, K. and T. Milligan, 1980. Macroflocs: the production of marine snow in the laboratory. Mar. Ecol. Prog. Ser., 3, 19-24. 
Kranck, K. and T.G. Milligan, 1988. Macroflocs from diatoms: in situ photography of suspended particles in Bedford Basin, N.S., Mar. Ecol. Prog. Ser., 44: 183-189.

Kranck, K. and T. G. Milligan, 1991. Grain size in oceanography, In Theory, Methods and Applications of Particle Size Analysis. Syvitski, J. P. (ed.). Cambridge University Press, New York, 332-345.

Kranck, K. and T.G. Milligan, 1992. Characteristics of suspended particles at an 11 hour anchor station in San Francisco Bay, California, J. Geophys. Res., 97, C7, 11,37311,382 .

Kranck, K., E. Petticrew, T.G. Milligan, I. Droppo, 1992. In-situ particle size distributions resulting from flocculation of suspended sediment, in: Nearshore and Cohesive Sediment Transport, A. J. Mehta (ed.), Coastal and Estuarine Studies Ser., 42(60-75), Springer-Verlag, N.Y.

Krone, R.B., 1962. Flume studies of the transport of sediment in estuarial shoaling processes, Hydr. Engr. Lab. and Sanitary Engr. Res. Lab., U. California, Berkeley, Final Report to San Francisco district U.S. Corps of Engineers.

Leussen, W. van., 1986. Laboratory experiments on the settling velocity of mud flocs, in S.Y. Wang, H.W. Shen and L.Z. Ding eds. Proc. Third Int Symp. River Sedimentation, School of Engineering, Univ. of Mississippi,1803-1812.

Leussen, W. van, 1988. Aggregation of particles, settling velocity of mud flocs a review, In: Physical Processes in Estuaries, in J. Dronkers and W. van Leussen (eds), Physical Processes in Estuaries. Springer-Verlag, Berlin, New York, 404-426.

Leussen, W. van, and J.M. Cornelisse, 1993. The determination of the sizes and settling velocities of estuarine flocs by an underwater video system. Neth. J. Sea Res., $31(3), 231-241$.

Lick, W and J. Lick, 1988. Aggregation and disaggregation of fine-grained lake sediments, J. Great Lakes Res. 14, 4, 514-523.

Lick, W., H. Huang and R. Jepsen, 1993. Flocculation of fine-grained sediments due to differential settling. J. Geophys. Res. 98, 6, 10,279-10,288.

Logan, B.E. and J.R. Kilps, 1995. Fractal dimensions of aggregates formed in different fluid mechanical environments, Wat. Res., 29, 2, 443-453. 
Luettich, R.A., Jr., J.T. Wells and S.Y. Kim, 1993. In situ variability of large aggregates: Preliminary results on the effect of shear, in: A.J. Mehta, ed., Nearshore and Estuarine Cohesive Sediment Transport, Coastal and Estuarine Studies Ser., 42, 447-466.

Mehta, A.J. and E. Partheniades, 1975. An investigation of the depositional properties of flocculated fine sediments, Journal of Hydraulic Research, 13, 4, 361-381.

Milligan, T.G., 1995. An examination of the settling behaviour of a flocculated suspension, Neth. J. Sea Res., 33, 2, 163-171.

Milligan, T.G. and K. Kranck, 1991. Electro-resistance particle size analysers, In Theory, Methods and Applications of Particle Size Analysis. Syvitski, J. P. (ed.), Cambridge University Press, New York, 109-118.

Muhle, K., 1993. Floc stability in laminar and turbulent flow, in: D. Dobiáś ed. Coagulation and Flocculation: theory and application, Lib. Congress Surfactant Sci. Ser., 47, 355-390.

Muschenheim, D.K., 1987. The dynamics of near-bed seston flux and suspension-feeding benthos, J. Mar. Res., 45: 473-496.

Muschenheim, D.K., P.E. Kepkay and K. Kranck, 1989. Microbial growth in turbulent suspension and its relation to marine aggregate growth, Neth. J. of Sea Res., 23(3), 283-292.

Muschenheim, D.K., T.G. Milligan and D.C. Gordon, 1995a. New technology and suggested methodologies for monitoring particulate wastes discharged from offshore oil and gas drilling platforms and their effects on the benthic boundary layer environment, Can. Tech. Rep. Fish. Aquat. Sci., 2049, $x+55 p p$.

Muschenheim, D.K., T.G. Milligan, G.D. Steeves and M.B. Chin-Yee, 1995b. Imaging techniques and image analysis of particulate discharges from offshore oil and gas installations, in: Proc. Can. Coastal Conf., Can. Coastal Sci. Eng. Assoc., Ottawa, 637-650.

Muschenheim, D.K. and T.G. Milligan, 1996. Flocculation and accumulation of fine drilling waste particles on the Scotian Shelf, Mar. Pollution Bul., 32, 10, 740-745.

Niven, S.E.H., P.E. Kepkay and A. Boraie, 1995. Colloidal organic carbon and colloidal 234Th dynamics during a coastal phytoplankton bloom. Deep Sea Res. II, 42, 1, 257-273. 
Oles, V., 1991. Shear-induced aggregation and breakup of polystyrene latex particles, J. Colloid. Interface Sci., 154, 2, 351-358.

Olphen, H. van, 1963. An Introduction to Clay Colloid Chemistry, Interscience Publishers, N.Y., 301 pp.

Ortner, P.B., L.C. Hill and H.E. Edgerton. 1981, In-situ silhouette photography of Gulf Stream zooplankton, Deep-sea Res., 28A, 12, 1569-1576.

Ortner, P.B., S.R. Cummings, R.P. Aftring and H.E. Edgerton, 1979. Silhouette photography of oceanic zooplankton, Nature, 277, 50-51.

Owen, M.W., 1976. Determination of the settling velocity of cohesive muds, Hydraulics Res. Station Wallingford, Rep. No. IT 161, 26pp.

Pandya, J.D. and L.A. Spielman, 1982. Floc breakage in agitated suspensions: Theory and data processing strategy, J. Colloid Interface Sci., 92, 2, 517-531.

Passow,U., A.L. Alldredge and B.E. Logan, 1994. The role of particulate carbohydrate exudates in the flocculation of diatom blooms, Deep-Sea Res., 42, 2, 335-337.

Postma, H., 1967. Sediment transport and sedimentation in the marine environment. In: Estuaries, G.H. Lauff, ed., Am. Ass. Adv. Sci., 158-179.

Puls, W.H., H. Kuehl and K. Heyman, 1988. Settling velocity of mud flocs: results of field measurements in the Elbe Estuary. in: J. Dronkers and W. Van Leussen. Physical processes in estuaries. Springer Verlag, Berlin, New York: 406-426.

Russ, J.C., 1995. The Image Processing Handbook. 2nd ed.. CRC Press. New York. $674 \mathrm{pp}$.

Spicer, P.T. and S.E. Pratsinis, 1996. Shear induced flocculation: The evolution of floc structure and shape of the size distribution at steady state, Wat. Res., 50, 5, 10491056.

Syvitski, J.P.M., K.W. Asprey and K.W.G. LeBlanc, 1995. In situ characteristics of particles settling within a deep-water estuary. Topical Studies in Oceanography, $42,1,223-256$.

Tambo, N. and H. Hozumi, 1979. Physical characteristics of flocs - II. Strength of floc, Wat. Res., 13, 421-427. 
Ten Brinke, W.B.M., 1994. In situ aggregate size and settling velocity in the Oosterschelde tidal basin (The Netherlands), Neth. J. Sea Res., 32(1):23-35.

Tennekes, H. and J.L. Lumley, 1972. A first course in turbulence, MIT Press, Cambridge Ma., 300 pp.

Tsai, C.H., S. Iacobellis and W. Lick, 1987. Flocculation of fine-grained lake sediments due to a uniform shear stress, J. Great Lakes Res., 13920, 135-146.

Wilkinson, L., M. Hill, J.P. Welna and G.K. Birkenbeuel, 1992. SYSTAT for Windows: Statistics, Ver. 5 edition, SYSTAT Inc., Evanston, Il. 750pp. 

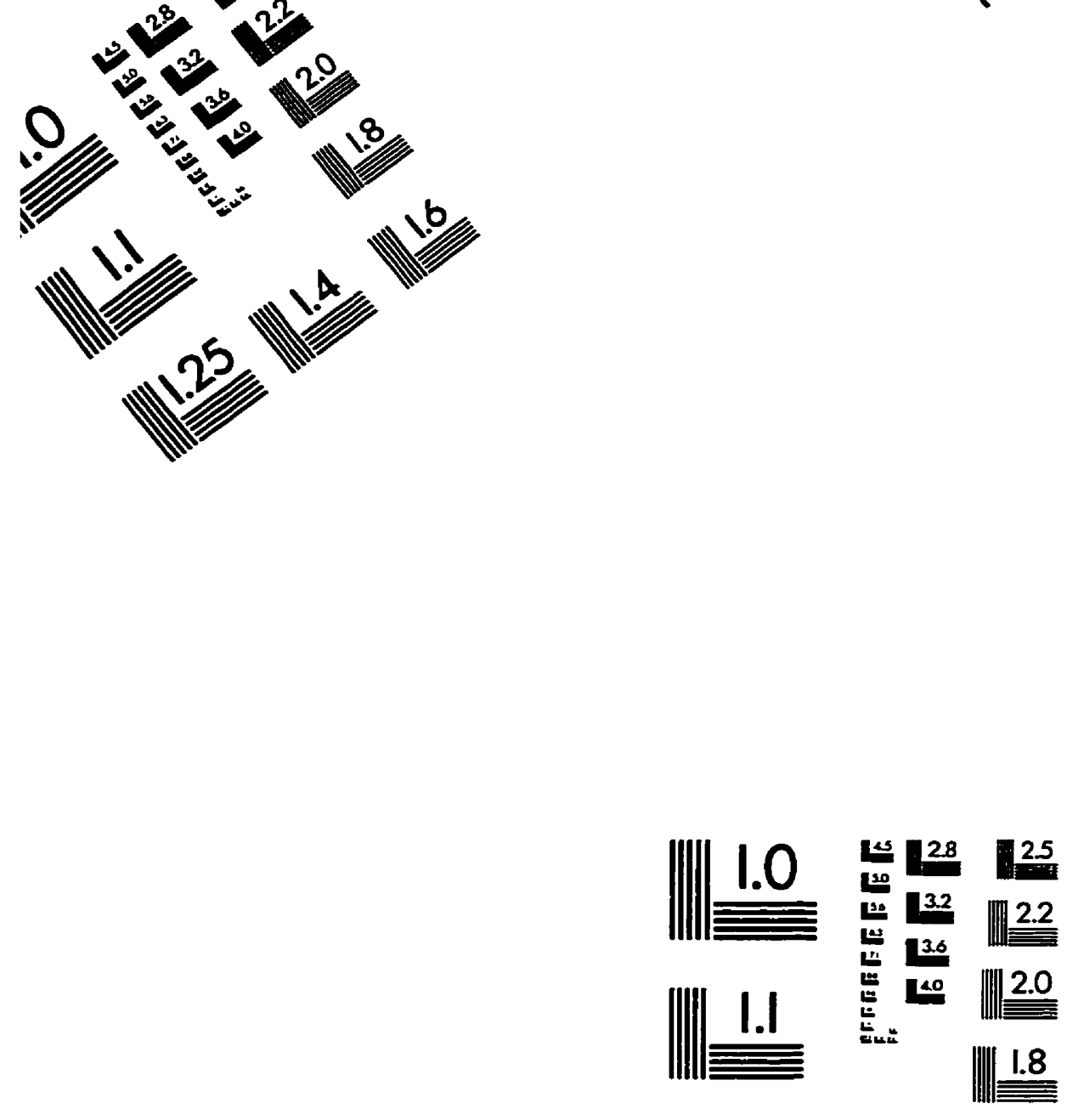

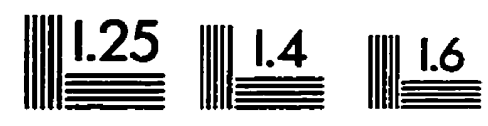
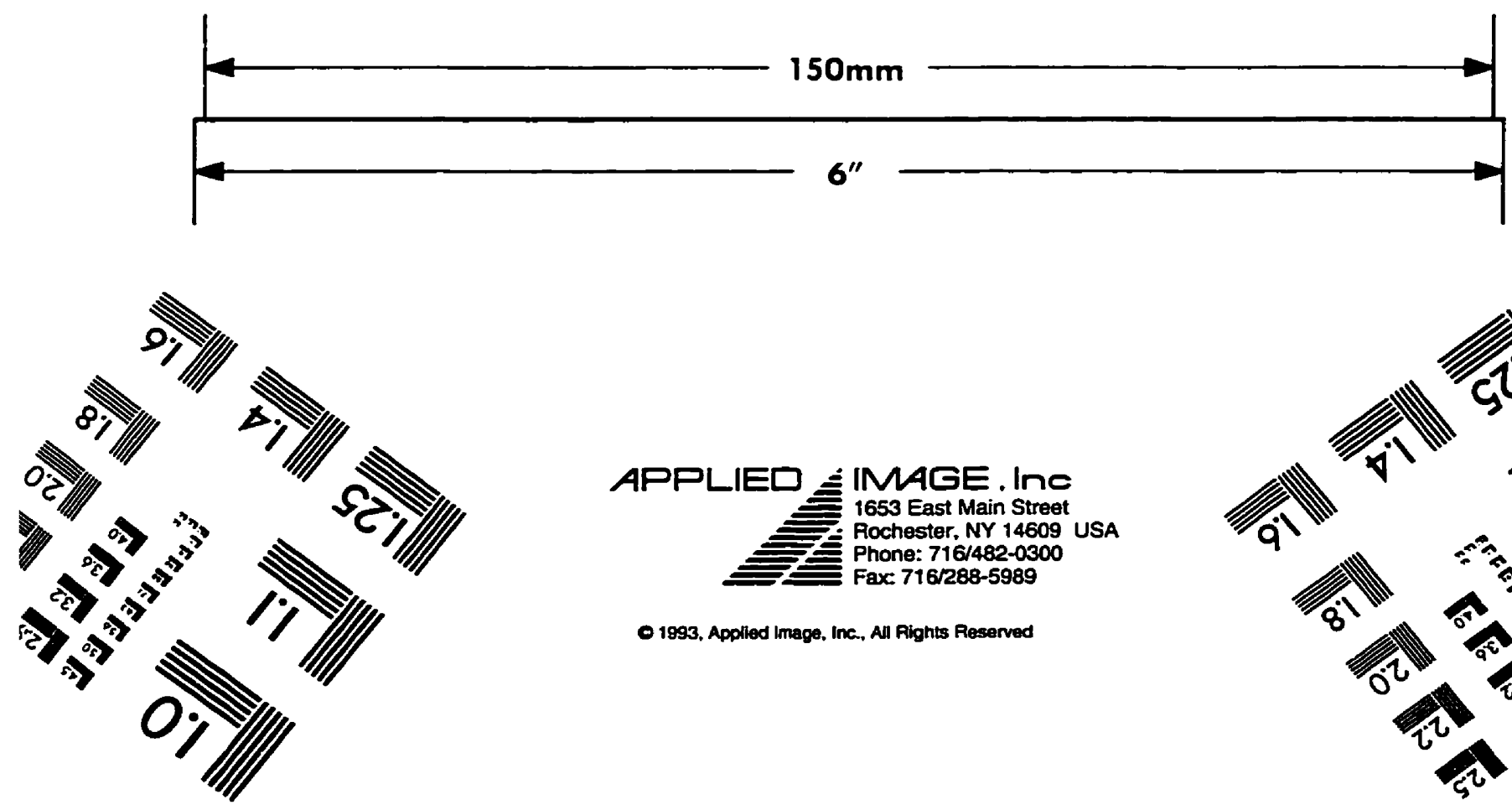

- 1993, Applied Image, Inc., All Rights Reserved

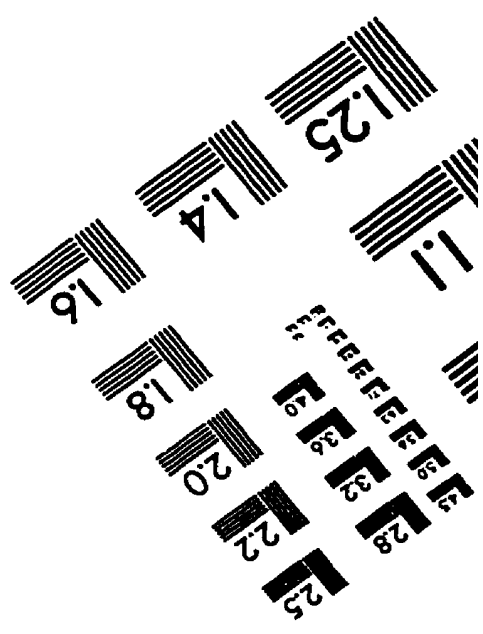

